\title{
Review Article \\ Nuclear Control of the Inflammatory Response in Mammals by Peroxisome Proliferator-Activated Receptors
}

\author{
Stéphane Mandard ${ }^{1}$ and David Patsouris ${ }^{2,3}$ \\ ${ }^{1}$ Centre de Recherche INSERM-UMR866 "Lipides, Nutrition, Cancer" Faculté de Médecine, Université de Bourgogne 7, \\ Boulevard Jeanne d'Arc, 21079 Dijon Cedex, France \\ ${ }^{2}$ Laboratoire CarMeN, UMR INSERM U1060/INRA 1235, Université Lyon 1, Faculté de Médecine Lyon Sud, \\ 165 Chemin du Grand Revoyet, 69921 Oullins, France \\ ${ }^{3}$ Department of Chemical Physiology, The Scripps Research Institute, MB-24, 10550 North Torrey Pines Road, La Jolla, CA 92037, USA
}

Correspondence should be addressed to Stéphane Mandard; stephane.mandard@u-bourgogne.fr

Received 15 October 2012; Revised 14 January 2013; Accepted 29 January 2013

Academic Editor: Massimo Bionaz

Copyright (C) 2013 S. Mandard and D. Patsouris. This is an open access article distributed under the Creative Commons Attribution License, which permits unrestricted use, distribution, and reproduction in any medium, provided the original work is properly cited.

Peroxisome proliferator-activated receptors (PPARs) are ligand-activated transcription factors that play pivotal roles in the regulation of a very large number of biological processes including inflammation. Using specific examples, this paper focuses on the interplay between PPARs and innate immunity/inflammation and, when possible, compares it among species. We focus on recent discoveries establishing how inflammation and PPARs interact in the context of obesity-induced inflammation and type 2 diabetes, mostly in mouse and humans. We illustrate that PPAR $\gamma$ ability to alleviate obesity-associated inflammation raises an interesting pharmacologic potential. In the light of recent findings, the protective role of PPAR $\alpha$ and PPAR $\beta / \delta$ against the hepatic inflammatory response is also addressed. While PPARs agonists are well-established agents that can treat numerous inflammatory issues in rodents and humans, surprisingly very little has been described in other species. We therefore also review the implication of PPARs in inflammatory bowel disease; acute-phase response; and central, cardiac, and endothelial inflammation and compare it along different species (mainly mouse, rat, human, and pig). In the light of the data available in the literature, there is no doubt that more studies concerning the impact of PPAR ligands in livestock should be undertaken because it may finally raise unconsidered health and sanitary benefits.

\section{Introduction}

The peroxisome proliferator-activated receptors (PPARs) are ligand-activated transcription factors that play critical roles in very different biological pathways such as lipid, protein, glycerol, urea, glucose, glycogen and lipoprotein metabolism, adipogenesis, trophoblast differentiation, and cell migration [1-6]. Notably, PPARs are also required to balance cell proliferation and cell death and therefore impact skin wound healing and proliferative diseases such as cancer [7-9]. PPARs are also prominent players in inflammation control $[10,11]$. PPAR $\alpha$, the first PPAR isotype identified in mouse, was originally cloned in the early 1990s as a novel member of the steroid hormone receptor superfamily [12]. Shortly after, a rat version of PPAR $\alpha$ as well as three novel members related to each other (xPPAR $\alpha, x \operatorname{PPAR} \beta$, and $\mathrm{xPPAR} \gamma)$ and to mouse PPAR $\alpha$ have been subsequently cloned from Xenopus (frog) [13]. Since then, substantial efforts have been made to identify other related receptors; several additional PPAR isoforms and variants have been therefore isolated in a wide range of species including mammals (human, rabbit, mouse, rat, pig, rhesus and cynomolgus monkey, dog, guinea pig, hibernating ground squirrel, and hamster), fishes (grass carp, cobia not only but also marine fish such as the teleost red sea bream (Pagrus major) and the mullet Chelon labrosus), marine gastropod mollusks (Cyclostoma), reptiles (leopard gecko, crocodile, and turtle), and birds (domestic chicken, goose) [14-51].

Since PPARs are ligand-activated transcription factors, a large part of our knowledge about their biological importance is coupled to the function of their target genes. At the molecular level, it was shown that PPARs readily heterodimerize with 
the Retinoid X Receptor (RXR) prior to ligand binding [52]. In all species tested so far, Ppar, Ppar $\beta / \delta$, and Ppar $\gamma$ show specific time- and tissue-dependent patterns of expression (Table 1).

After ligand treatment, the PPAR/RXR heterodimer stably binds on genomic DNA at specific sites called Peroxisome Proliferator Response Element (PPRE) and upregulates gene transcription. Consensus PPREs are formed by two hexameric core binding motifs (AGGTCA) in a direct repeat orientation with an optimal spacing of one nucleotide (DR1). Molecular investigations have demonstrated that PPAR occupies the $5^{\prime}$ motif of the DR1 [53]. Recent analyses have further revealed that even if DR1 PPREs can be located within the promoter sequences of target genes, about $50 \%$ of all target sites are located within genes (introns, exons) as well as in $3^{\prime}$ downstream sequences of the target genes $[4,7,54-$ 58]. The PPAR $\alpha$ (NR1C1), PPAR $\beta / \delta$ (NR1C2), and PPAR $\gamma$ (NR1C3) genes encode proteins that share a highly conserved structure and molecular mode of action, yet the array of genes regulated by each PPAR isotype is divergent and may also differ from one species to another [59]. An extended analysis of the cross-species (mouse to human) conservation of PPREs brought support to this hypothesis because it revealed only limited conservation of PPRE patterns [60]. Strengthening this observation, only a minor overlap between the Wy14,643 (Wy: a specific PPAR $\alpha$ agonist) regulated genes from mouse and human primary hepatocytes was found by Rakhshandehroo et al. demonstrating that some, but not all, genes are equally regulated by PPAR $\alpha$ in mouse and human hepatocytes [61]. In this review, we explore and focus on the role of PPARs in the control of chronic (mediated by obesity) or acute (as a result of bacterial infection) inflammation in different species, mainly from human, mouse, rat, pig, and cow.

\section{PPARs and Obesity-Induced Inflammation: Interplay with Adipose Tissue Macrophages}

2.1. PPAR $\alpha$. In spite of the relative weak expression level of Ppard in white adipose tissue (WAT, mainly in adipocytes and not in stromal-vascular cells), several lines of evidence support the notion that PPAR $\alpha$ and PPAR $\alpha$ agonists could play a functional role in the control of obesity-induced chronic inflammatory response in vivo. For instance, treatment of obese diabetic KKAy mice with Wy decreased the mRNA levels of Tnf- $\alpha$ (tumor necrosis factor- $\alpha$ ), Mcp-1 (monocyte chemotactic protein-1, also referred to as chemokine (C-C motif) ligand 2, CCL2), and Mac-1 (macrophage antigen-1, also known as cluster of differentiation molecule-11b, Cd11b) in epididymal fat, suggesting a reduction in macrophage infiltration [62]. In addition, expression of inflammatory genes in adipose tissue such as Tnf- $\alpha, M c p-1$, and IL-1 1 (Interleukin-1 beta) as well as that of specific macrophage markers such as Cd68 (macrophage antigen Cd68, also known as scavenger receptor class D member 1, Scard1), F4/80 (also referred to as lymphocyte antigen-71, Ly71), and Adam8 (ADAM metallopeptidase domain 8 , also known as cluster of differentiation molecule-156, Cd156) in the stromal vascular fraction was more pronounced in Ppar $\alpha$-deficient mice compared to WT (wild-type) mice rendered obese with a high-fat feeding,
TABLE 1: Tissue distribution of the various PPARs in different species.

\begin{tabular}{|c|c|c|}
\hline Specie & Tissue & Expression \\
\hline \multicolumn{3}{|c|}{ PPAR $\alpha(\mathrm{NR} 1 \mathrm{C} 1)$} \\
\hline \multirow{5}{*}{ Cow/cattle } & Liver & $++[237]$ \\
\hline & WAT & N.D. \\
\hline & GI tract & N.D. \\
\hline & Brain & N.D. \\
\hline & Spleen/thymus & N.D. \\
\hline \multirow{4}{*}{ Chicken } & Liver & $++[23]$ \\
\hline & WAT & $+[82]$ \\
\hline & Brain & $++[82]$ \\
\hline & Spleen & $+[82]$ \\
\hline \multirow{12}{*}{ Human } & Liver & $\frac{+++}{[20,61,118,162,175]}$ \\
\hline & Primary hepatocytes & \pm to $+++[61,134]$ \\
\hline & HepG2 hepatoma cells & $+[54]$ \\
\hline & HepaRG hepatoma cells & $++[134]$ \\
\hline & WAT & $+[20,118,238]$ \\
\hline & Isolated adipocytes & $\pm[20]$ \\
\hline & GI tract & $++[20,118,175,239]$ \\
\hline & Brain & $+[118,175,240]$ \\
\hline & Monocytes & $+[241,242]$ \\
\hline & Dendritic cells & $++[241,242]$ \\
\hline & Kidney & $++[20,118]$ \\
\hline & Heart & $+++[118]$ \\
\hline \multirow{2}{*}{ Pig } & Liver & $\pm[243]$ \\
\hline & WAT & $+[243]$ \\
\hline \multirow{9}{*}{ Mouse/rat } & Liver & $+++[61,83,244-247]$ \\
\hline & Hepatocytes & $++[61]$ \\
\hline & GI tract & $++[$ Nursa $][175]$ \\
\hline & Brain & $+[$ Nursa $]$ \\
\hline & Spleen/thymus & $-[83]$ \\
\hline & Macrophages (BMDM) & $-[244]$ \\
\hline & FAO hepatoma cells & $++[54]$ \\
\hline & WAT & $+[62,248]$ \\
\hline & $\operatorname{PPAR} \beta / \delta(\mathrm{NR} 1 \mathrm{C} 2)$ & \\
\hline \multirow{5}{*}{ Cow/cattle } & Liver & N.D. \\
\hline & WAT & N.D. \\
\hline & GI tract & N.D. \\
\hline & Brain & N.D. \\
\hline & Spleen/thymus & N.D. \\
\hline \multirow{5}{*}{ Chicken } & Liver & N.D. \\
\hline & WAT & N.D. \\
\hline & GI tract & N.D. \\
\hline & Brain & N.D. \\
\hline & Spleen/thymus & N.D. \\
\hline
\end{tabular}


TABLE 1: Continued.

\begin{tabular}{|c|c|c|}
\hline Specie & Tissue & Expression \\
\hline \multirow{13}{*}{ Human } & Liver & $\pm[20]$ \\
\hline & HepG2 hepatoma cells & $++[54]$ \\
\hline & WAT & $\pm[20]$ \\
\hline & Isolated adipocytes & $\pm[20]$ \\
\hline & Large intestine & $+++[20]$ \\
\hline & Small intestine & $+[20]$ \\
\hline & Colon mucosae (adult) & $++[239]$ \\
\hline & Brain & N.D. \\
\hline & Monocytes & $++[241]$ \\
\hline & Macrophages & $+++[249]$ \\
\hline & Dendritic cells & $+[241]$ \\
\hline & Kidney & $+[20]$ \\
\hline & Skeletal muscle & $\pm[20]$ \\
\hline \multirow{4}{*}{ Pig } & Liver & $+[250]$ \\
\hline & WAT & $++[250]$ \\
\hline & Stomach & $++[250]$ \\
\hline & Brain & $++[250]$ \\
\hline \multirow{4}{*}{ Rabbit } & Liver & $\pm[251]$ \\
\hline & GI tract & $+[251]$ \\
\hline & Brain & $++[251]$ \\
\hline & Spleen/thymus & $\pm[251]$ \\
\hline \multirow{8}{*}{ Mouse/rat } & Liver & $\begin{array}{c}+ \text { to }++[\text { Nursa }] \\
{[50,83,246,247]}\end{array}$ \\
\hline & FAO hepatoma cells & $++[54]$ \\
\hline & WAT & $+[$ Nursa $][50]$ \\
\hline & GI tract & $+++[$ Nursa $][50,175]$ \\
\hline & Brain & $\begin{array}{c}+++[\text { Nursa }] \\
{[50,83,193,252]}\end{array}$ \\
\hline & Macrophages (BMDM) & $++[244]$ \\
\hline & Colon & $++[83]$ \\
\hline & PPAR $\gamma($ NR1C3) & \\
\hline \multirow{5}{*}{ Cow/cattle } & Liver & $-[253]$ \\
\hline & WAT & $+++[253,254]$ \\
\hline & Spleen/thymus & $++[253]$ \\
\hline & Small intestine & $\pm[253]$ \\
\hline & Mammary gland & {$[235]$} \\
\hline \multirow{4}{*}{ Chicken } & Liver & $-[82]$ \\
\hline & Spleen/thymus & $+[82]$ \\
\hline & Brain & $+[255]$ \\
\hline & WAT & $+++[255]$ \\
\hline \multirow{4}{*}{ Human } & Liver & $+[20,256,257]$ \\
\hline & HepG2 hepatoma cells & $+[54]$ \\
\hline & HepaRG cells & $\pm[134]$ \\
\hline & Primary hepatocytes & $\pm[134]$ \\
\hline
\end{tabular}

TABle 1: Continued.

\begin{tabular}{|c|c|c|}
\hline \multirow[t]{11}{*}{ Specie } & Tissue & Expression \\
\hline & WAT & $+++[20,54,256,257]$ \\
\hline & Isolated adipocytes & $+++[20]$ \\
\hline & $\begin{array}{l}\text { Simpson-Golabi-Behmel } \\
\text { Syndrome (SGBS) } \\
\text { adipocytes }\end{array}$ & $+++[84]$ \\
\hline & Large intestine & $+++[20]$ \\
\hline & Small intestine & $\pm[20]$ \\
\hline & Brain & N.D. \\
\hline & Monocytes & $+++[241]$ \\
\hline & Dendritic cells & $+++[241]$ \\
\hline & Kidney & $+[20]$ \\
\hline & Skeletal muscle & $\pm[20]$ \\
\hline \multirow{2}{*}{ Pig } & Liver & $-[243]$ \\
\hline & WAT & $++[243]$ \\
\hline \multirow{5}{*}{ Rabbit } & Liver & - to $+[251,258]$ \\
\hline & WAT & $+++[258]$ \\
\hline & GI tract & $+++[251]$ \\
\hline & Brain & $-[251]$ \\
\hline & Spleen/thymus & $++[251]$ \\
\hline \multirow{9}{*}{ Mouse/rat } & Liver & $\begin{array}{l}+ \text { to }-[\text { Nursa }] \\
{[83,246,247]}\end{array}$ \\
\hline & Hepatocytes & $+[259]$ \\
\hline & FAO hepatoma cells & $-[54]$ \\
\hline & WAT & $\begin{array}{c}+++[\text { Nursa }] \\
{[83,256,260]}\end{array}$ \\
\hline & 3T3-L1 adipocytes & $+++[84]$ \\
\hline & GI tract & $+[$ Nursa $][83]$ \\
\hline & Brain & $\begin{array}{c}+[\text { Nursa }] \\
{[83,261,262]}\end{array}$ \\
\hline & Spleen/thymus & $++[83]$ \\
\hline & Macrophages (BMDM) & $+++[244]$ \\
\hline
\end{tabular}

Abbreviations: GI: gastrointestinal; WAT: white adipose tissue; N.D.: not determined. BMDM: bone marrow-derived macrophages.

Symbols: -: absent; \pm : barely detectable; +: weak; ++: moderate; +++: high. the citation link for Nursa is http://www.nursa.org/10.1621/datasets.02001.

reinforcing the notion that PPAR $\alpha$ is required for the control of the adipose inflammation process [63]. Another study has also examined the effects of fibrates on the inflammatory changes induced by the interaction between adipocytes and macrophages in obese adipose tissue. Systemic administration of Wy or fenofibrate to genetically obese $o b / o b$ mice significantly reduced Tnf- $\alpha$ and Mcp-1 mRNA expression in WAT [64]. Similar observation was also reported using adipose tissue explants from $o b / o b$ mice suggesting a direct effect of PPAR $\alpha$ agonists. To check for the definitive involvement of PPAR $\alpha$ in the effects of Wy-mediated reduction in the production of proinflammatory cytokines by white fat pads, adipose tissue explants obtained from PPAR $\alpha$-deficient 
mice were also used [64]. Compared to WT mice, induction of Mcp-1 mRNA expression by TNF- $\alpha$ (a major paracrine mediator of inflammation in adipocyte) was much robust in adipose tissue explants from Ppar $\alpha$-deficient mice, suggesting that PPAR $\alpha$ is constitutively required to control the steady-state level of adipose $M c p-1 \mathrm{mRNA}$ levels. Intriguingly, induction of adipose $M c p-1$ mRNA expression by TNF- $\alpha$ was also suppressed by Wy in explants from Ppar $\alpha$-deficient mice, suggesting that Wy can act independently of the presence of the receptor in fat, at least for the control of the inflammation process [64]. Because Ppary is expressed in both mature adipocytes and macrophages, we cannot rule out that part of the effects of fibrates on adipose inflammation are mediated through this other PPAR isotype. Moreover, treating 3T3L1 mouse adipocytes with Wy or fenofibrate suppressed bacterial lipopolysaccharides-(LPS-) mediated increased in Mcp-1 mRNA levels, indicating a cell autonomous effect [62]. Interestingly, pharmacological activation of PPAR $\alpha$ also reduced LPS-mediated induction of Mcp-1 mRNA level in peritoneal macrophages. Therefore, it is possible that PPAR $\alpha$ agonists mediate reduction of the inflammatory response in both adipocytes and infiltrated macrophages in WAT. Whether adipose PPAR $\alpha$ is a critical factor for the control of adipose inflammation remains a matter for further study. To close this gap, it could be interesting in the future to check for the consequence of the selective deletion of Ppara in WAT, using the Cre/loxP strategy and the adipocyte/macrophagespecific aP2 (a-FABP) promoter [65].

2.2. PPAR $\beta / \delta$. While ubiquitously expressed, probably in all cells found in WAT, PPAR $\beta / \delta$ is also the isotype whose exact roles in the control of WAT function and type- 2 diabetes in general are the least clear. Firstly, PPAR $\beta / \delta$ undoubtedly displays anti-inflammatory properties in numerous cell types present in WAT, such as macrophages, adipocytes, and endothelial cells [66]. In agreement, it was found that activation of PPAR $\beta / \delta$ prevents LPS-induced NF- $\kappa$ B (a key regulatory proinflammatory transcription factor) activation by regulating ERK1/2 (Extracellular signal-Regulated Kinases) phosphorylation in adipocytes and WAT in mice [67]. PPAR $\beta / \delta$ may therefore represent an interesting target for the treatment of inflammatory diseases such as atherosclerosis [68]. Secondly, several investigations aiming to determine the role of $\operatorname{PPAR} \beta / \delta$ in WAT mass have demonstrated that it probably only plays a moderate role in adipogenesis and an indirect role in the control of WAT mass [69-72]. For instance, feeding murine models of obesity and diabetes with a PPAR $\beta / \delta$ agonist decreases their adiposity [73]. Yet, these effects are most likely mediated by $P$ par $\beta / \delta$ expression in other nonadipose tissues such as liver and skeletal muscle because WAT $P$ par $\beta / \delta$ conditional knockout mice do not exhibit any apparent adipose tissue phenotype [70]. Furthermore, this indirect role of PPAR $\beta / \delta$ is also provided in mice overexpressing Ppar $\beta / \delta$ in skeletal muscle because these mice display decreased adiposity and adipocyte size [74]. Regarding WAT inflammation, several publications have led to discrepant findings as well. For instance, reconstitution with $P \operatorname{par} \beta / \delta$ null bone marrow of irradiated WT mice to generate $P$ par $\beta / \delta$ null animals lacking $P$ par $\beta / \delta$ in hematopoietic cells had no clear effects on WAT inflammation and insulin sensitivity. If any benefits on insulin sensitivity were seen, these were different according to the genetic background of the mice and likely mediated by the liver where PPAR $\beta / \delta$ switches the phenotype of Kupffer cells (liver macrophageslike cells) into an anti-inflammatory phenotype (also called M2 phenotype; this phenotype is acquired after cell activation by cytokines such as Interleukin- 4 and Interleukin-13) $[66,75]$. Classically, activated macrophages (also known as M1 type) express high levels of proinflammatory mediators that elevate inflammation to a low, but chronic, grade and contribute to insulin resistance [76, 77]. In contrast, M2 "alternatively" activated macrophages are characterized by low production of proinflammatory cytokines (including IL-1 $\beta$, TNF- $\alpha$, and IL-6) and high production of antiinflammatory cytokines (including IL-10), by a gene expression profile distinct from other macrophage populations and by their capacity to scavenge debris, to promote angiogenesis, tissue repair, and remodeling [78]. However, the observations evoked above contrast with that of Kang et al. who describe that $\operatorname{PPAR} \beta / \delta$ is required for the polarization of adipose tissue macrophages (ATMs) into an M2 phenotype [79]. In summary, the exact role of PPAR $\beta / \delta$ in the control of WAT inflammation requires further investigations.

2.3. PPAR $\gamma$. In response to an inappropriate diet, insulin resistance settles in WAT further limiting its capacity to store fat. Consequently, excess fatty acids overflow into other organs such as skeletal muscle and liver (ectopic fat), which in turn alters proper functioning of these tissues [80]. PPAR $\gamma$ is strongly associated with obesity because it is highly expressed in white fat depots and it serves as a target for certain antidiabetic drugs. A substantial amount of Ppar 1 mRNA level is detected in many tissues including white and brown adipose tissue, skeletal muscle, liver, colon, bone, and placenta and cell types such as pancreatic $\beta$-cells and macrophages in different species ranging from humans to rodents, sheep and cattle [81]. The other Ppary isoform, Ppar 2 2, is highly expressed in WAT in rodents (mainly rats and mice) as well as in humans, chicken, and sheep [20, 82-86].

A wealth of studies has established the critical role of PPAR $\gamma$ in adipose tissue biology and it is now widely accepted that PPAR $\gamma$ is a predominant nuclear receptor regulating the process of adipose differentiation both in vivo and in vitro [87-89]. However, it now appears that it is more specifically the low-grade systemic inflammation associated with obesity that is central to the etiology of the disease. During development of obesity, the expansion of WAT is accompanied with increased infiltration of macrophages that accumulate around stressed mature adipocytes [90]. Several genetic and pharmacological manipulations have further revealed situations in which obesity and inflammation were disconnected, demonstrating that obesity as such does not necessarily leads to type-2 diabetes as long as inflammation does not occur [77, 91-93]. In the context of obesity, adipocytes are exposed to excessive concentrations of free fatty acids. We and others have recently demonstrated that various fatty acids, especially arachidonic acid, induce the murine adipose transcription and secretion of chemokines such as MCP-1, 
Regulated upon Activation, Normal T-cell Expressed and Secreted/chemokine (C-C motif) ligand 5 (RANTES/CCL5), and the chemokine Keratinocyte Chemoattractant (KC, also known as CXCL1) [94-96]. As chemokines govern the recruitment of leukocytes such as macrophages, high-fat diets providing elevated levels of fatty acids are likely to cause the adipose secretion of chemokines. In turn, these chemokines will induce the recruitment of macrophages in WAT and elevate local inflammation (Figure 1).

Detailed analysis of the molecular mechanisms involved revealed that the activation of the Toll-like receptor 4 pathway (TLR4) by the fatty acids was required. Surprisingly, activation of this pathway causes the decreased expression level of Ppary, which was prevented by the cotreatment with ER stress inhibitors [94]. This observation adds up to other publications demonstrating the key, yet unstable, role played by this specialized organelle in maintaining an adequate cellular response to metabolic stresses $[97,98]$. Together, this led us to establish a model in which fatty acids, through a TLR4/ ER stress-dependent pathway, induce the recruitment of leukocytes by increasing the secretion of chemokines [99].

In spite of decreased Ppary mRNA levels, pharmacological activation of PPAR $\gamma$ with rosiglitazone (RSG), a thiazolidinedione (TZD)/PPAR $\gamma$ agonist, prevents fatty acid-mediated adipose induction of chemokines expression and secretion $[94,100]$. These observations were strengthened by in vivo experiments where treatments of mice fed a high-fat diet by RSG increased adiposity but decreased the expression of chemokines by adipocytes, the classically activated adipose tissue macrophages (M1 type) content and WAT inflammation $[77,94,101]$. Therefore, PPAR $\gamma$ maintains the expression of chemokines to a minimal level in adipocytes. As a member of the nuclear hormone receptor superfamily, PPAR $\gamma$ displays both transactivational and transrepressional activities $[59,102]$. Interestingly, it is likely through transrepressional activity that PPAR $\gamma$ affects chemokines secretion by adipocytes [94]. In line with this, it is worth mentioning the recent discovery of MBX-102/JNJ39659100, a member of a novel non-TZD class of selective partial PPAR $\gamma$ agonist with weak transactivational activity, yet high transrepressional activity for $\operatorname{PPAR} \gamma$, that conserves insulin-sensitizing properties without inducing well-known major side effect [103]. As PPAR $\gamma$ transrepressional activity is involved in the repression of proinflammatory cytokines and chemokines, it is tempting to think that part of TZDs therapeutic properties on type2 diabetes could be explained by their anti-inflammatory properties. Therefore, developing agents able to disconnect the transactivational activity of PPAR $\gamma$ from its transrepressional activity may represent an effective strategy to treat different inflammatory diseases such as type- 2 diabetes. This hypothesis raises the fundamental question about how does PPAR $\gamma$ transrepressional activity work? Elucidation of the basic mechanism on how PPAR $\gamma$ controls inflammation has derived primarily from work performed in macrophages [104-106]. As PPAR $\gamma$ transrepressional activity is also involved in the repression of proinflammatory cytokines in the stromal vascular cells of WAT (i.e., the macrophage containing cellular fraction), similar molecular mechanisms of regulation may also occur in adipocytes and macrophages, but it is a nonproven hypothesis at the moment. The scenario is probably as follows: in resting situation, constant binding of corepressors complexes such as nuclear receptor corepressor (NCOR) and silencing mediator for retinoid and thyroid hormone receptors (SMRT) on the gene promoter sequence of these cytokines and chemokines prevent their expression [106]. When an inflammatory stimulus is applied, NCOR becomes ubiquitinated further excluding these complexes from the nucleus. In addition, coactivators are recruited to the promoter of cytokines and transcription of the gene occurs. However, when activated by an agonist of the TZD family, PPAR $\gamma$ becomes SUMOylated and docked to the corepressor complexes [107, 108]. Association between PPAR $\gamma$ and NCOR prevents its ubiquitination further maintaining the expression of chemokines and cytokines in a repressed state. The contribution of PPARs in disconnecting obesity and inflammation is illustrated in genetic models where PPAR isotypes were selectively invalidated in macrophages and bone marrow-derived cells. First, when Ppary is invalidated in macrophages, mice become more susceptible to develop insulin resistance, a state that is accompanied with elevated local inflammation in liver, adipose, and skeletal muscle tissues $[109,110]$. All the above observations were explained by the shift of macrophages into a proinflammatory (M1 type) phenotype [110]. In consequence, one major role of PPAR $\gamma$ in macrophages is to maintain this population in an alternative anti-inflammatory state (M2 type) expressing genes such as the anti-inflammatory cytokine Interleukin-10, the IL-1 receptor antagonist (IL1-Ra), and arginase I [111, 112].

Another mechanism by which PPAR $\gamma$ controls adipose tissue macrophage polarization in coordinating the metabolism of macrophages. Indeed, classical (M1) activation of macrophages is a highly energy demanding state, which is sustained by glycolytic activity. Alternative (M2) activation of macrophages is less energy demanding and represents a state in which energy supplies are provided by oxidation of fatty acids and glucose. Interestingly, Odegaard and Chawla demonstrated that PPAR $\gamma$ is required to coordinate the oxidative genetic program in macrophages [113]. In support of this notion, it was also demonstrated that the expression of Ppary in macrophages is under the control of the pro-M2 cytokine Interleukin-4, which further involves the activation of STAT6 (signal transducer and activator of transcription 6). Finally, PPAR $\gamma$ requires the transcriptional coactivator PGC$1 \beta$ (peroxisome proliferator-activated receptor-gamma coactivator-1) in order to induce the oxidative program supporting macrophages alternative activation. Altogether, this series of observations illustrates that macrophage polarization involves different metabolic pathways that are necessary to sustain their energetic demand, and that PPAR $\gamma$ is coordinating this metabolic activity [113, 114].

Besides macrophages, invasion of WAT by neutrophils, eosinophils, B cells, T cells, and mast cells has been also reported. Recently, a small subset of $\mathrm{T}$ lymphocytes, the CD4 (+) Foxp3 (+) T regulatory (Treg), were abundantly found in the WAT of normal (lean) but not in different mouse models of obesity [115]. Interestingly, elegant studies have demonstrated that Treg cell depletion in the abdominal adipose tissue led to the induction of proinflammatory 


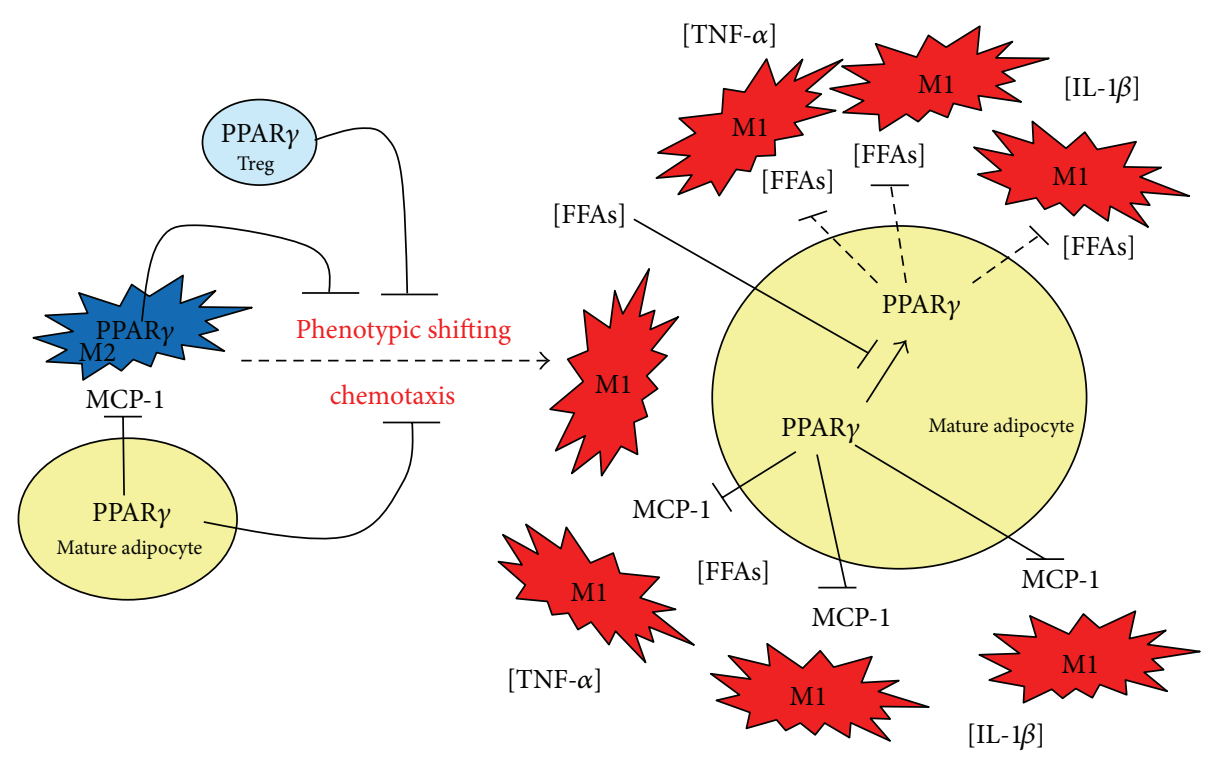

FIGURE 1: Contribution of the anti-inflammatory roles of PPAR $\gamma$ in the onset of WAT inflammation in the context of obesity and insulin resistance. In the lean state, PPAR $\gamma$ activity maintains homeostasis in mature adipocytes in preventing the secretion of chemokines such as MCP-1. In addition, alternatively activated macrophages (M2) and Treg cells are resident leukocytes in WAT coordinating numerous biological activities such as stimulating angiogenesis and cleaning of dead cells. The role of PPAR $\gamma$ in these cells is to prevent classical activation of macrophages and local inflammation to develop. When obesity is reached, mature adipocytes are exposed to excessive concentrations of free fatty acids (FFAs), which decrease Ppary expression. In consequence, insulin sensitivity is also decreased in adipocytes, which elevates even more local FFAs concentrations as adipocytes are no longer able to properly store fatty acids and lipolysis also becomes activated. Furthermore, these FFAs activate macrophages shifting into an M1 phenotype, promoting the release of proinflammatory cytokines such as TNF- $\alpha$ and IL-1 $\beta$. Secondly, as PPAR $\gamma$ transrepressional activity is decreased, adipocytes secrete high concentrations of chemokines (MCP-1), further promoting the recruitment of macrophages. Occurrence of this feed forward amplification loop between adipocytes and macrophages eventually leads to the elevation of local inflammation, further exacerbating local insulin resistance, which will turn systemic in the long term. MCP-1: monocyte chemoattractant protein-1; treg cells: regulatory T cells; FFA: free fatty acids; PPAR $\gamma$ : peroxisome proliferator-activated receptor $\gamma$; TNF- $\alpha$ : tumor necrosis factor-alpha; IL-1 $\beta$ : Interleukin-1 beta.

transcripts and enhanced inflammatory state of murine WAT [115]. Very recently, Cipolletta et al. found that deleting mouse Ppary in Treg cells markedly influences the number of Treg cells residing specifically in WAT and pioglitazone, a synthetic/TZD agonist of PPAR $\gamma$, and increases substantially the WAT Treg cell population in WT obese animals fed a high-fat diet [116, 117]. Furthermore, the ability of TZDs to downregulate the inflammatory state of WAT and to improve insulin sensitivity was impaired in specific Ppar $\gamma$-deficient Treg cells. In conclusion, this information indicates that regulatory T cells expressing Ppary are engaged in suppressing adipose tissue inflammation in obesity. Furthermore, PPAR $\gamma$ not only plays an important role in adipose macrophages but also in Treg cells. Further studies are required in order to test whether PPAR $\gamma$ may play a role in other immune cells controlling adipose tissue inflammation and whether this finding can be translated in other species such as humans.

\section{PPARs and Inflammation in Liver}

3.1. PPAR $\alpha$. In rodents, Ppar $\alpha$ is abundantly expressed in liver where it regulates a whole array of genes involved in the uptake, binding and degradation of fatty acids by mitochondrial and peroxisomal $\beta$-oxidation, as well as in lipoprotein assembly, transport and inflammation [118, 119]. More than a decade ago, as PPAR $\alpha$ is the nuclear receptor for the eicosanoid leukotriene B4 but also for the palmitoylethanolamide (the naturally occurring amide of palmitic acid and ethanolamine), a role for this nuclear receptor in modulating inflammation was evoked [11, 120,121]. Since then, a solid body of evidence has implicated PPAR $\alpha$ in the duration of inflammation control because prolonged inflammatory response was observed in mice lacking Ppar $\alpha$, suggesting anti-inflammatory actions for this nuclear receptor [11, 122].

3.1.1. Role of PPAR $\alpha$ in the Control of Obesity-Induced Inflammation in Liver. The role of PPAR $\alpha$ in inflammation has also been studied in the context of obesity-induced chronic low-grade inflammation, which is characterized by increased circulating inflammatory cytokines and acute-phase proteins $[123,124]$. Elegant experiments with Sv129 mice lacking the nuclear receptor Ppara and rendered obese by chronic highfat feeding displayed an increased abundance of macrophages in liver [63]. In agreement with this observation, mRNA 
levels of proinflammatory genes were markedly increased in Ppar $\alpha$-deficient mice fed high fat diet. Because PPAR $\alpha$ is a master regulator of fatty acid $\beta$-oxidation, PPAR $\alpha$ may indirectly inhibit inflammation by preventing fat accumulation in liver. However, treatment of mice under nonsteatotic conditions with Wy supports the notion that PPAR $\alpha$ is able to downregulate expression of inflammatory genes in liver independently of its effect on hepatic lipid storage [63]. Hence, by reducing hepatic lipid storage (and therefore lipotoxicity) and by suppressing proinflammatory gene expression in liver, PPAR $\alpha$ may protect mice from steatohepatitis. These findings were further strengthened by the work of Lalloyer and collaborators who studied the impact of Ppar $\alpha$ deletion in apoE2-KI mice (a human like hyperlipidemic mouse model) that were subjected to a Western diet supplemented or not with fenofibrate [125]. These ApoE2-KI Pparaknockout (-I-) mice displayed exaggerated liver steatosis and inflammation. Notably, reduced expression of inflammatory markers and macrophage content was observed in WT mice fed fenofibrate but not in Ppara-knockout mice, highlighting the functional role of PPAR $\alpha$ in hepatic inflammation control. Because fenofibrate treatment immediately reduced the expression of inflammatory genes, it was proposed that the beneficial effect of fenofibrate on hepatic lipid disorders (nonalcoholic steatohepatitis) could partly be due to its inhibitory effect on proinflammatory genes [126].

Inasmuch as PPAR $\alpha$ is a critical regulator of the hepatic inflammation process, the understanding of how Ppar $\alpha$ expression in the hepatocyte is regulated could provide substantial clues to fight inflammation. In mice, liver Ppara expression and PPAR $\alpha$ activity are strongly reduced by IL$1 \beta$, a cytokine produced by Kupffer cells, the resident macrophages of the liver [127]. From a molecular point of view, the inhibitory effect of IL- $1 \beta$ on Ppar $\alpha$ promoter activity is mediated by the binding of NF- $\kappa \mathrm{B}$ to two NF- $\kappa \mathrm{B}$ binding sites located in the promoter of the Ppara gene. Noteworthy, similar molecular mechanism is also observable with the human version of the PPAR $\alpha$ promoter, suggesting possible translation to the human situation. Therefore, strategies aiming at reducing Kupffer cell-derived IL- $1 \beta$ could theoretically limit the expansion of inflammation, at least in liver.

3.1.2. PPAR $\alpha$ and the Control of Inflammatory Gene Expression by Transrepression. In addition to upregulation of gene expression, a growing body of evidence in the scientific literature indicates that PPAR $\alpha$ also displays significant transrepressional activities on inflammatory genes. In agreement, PPAR $\alpha$ has been shown to interfere with several proinflammatory transcription factors including STAT, activator protein-1 (AP-1), nuclear factor-kappa B (NF- $\kappa \mathrm{B})$, and nuclear factor of activated T cells (NFAT). NF- $\kappa$ B activity is tightly controlled by the degradation of the inhibitory protein $\mathrm{I} \kappa \mathrm{B}$-alpha $(\mathrm{I} \kappa \mathrm{B} \alpha)$ that retains NF- $\kappa \mathrm{B}$ dimers in a nonactive form in the cytoplasm. It is worth recalling that PPAR $\alpha$ upregulates the expression of $\mathrm{I} \kappa \mathrm{B} \alpha$ in human aortic smooth muscle cells as well as in primary human hepatocytes [128]. Upon activation of $\mathrm{I} \kappa \mathrm{B} \alpha$, the nuclear translocation and DNA-binding activity of the proinflammatory transcription factor NF- $\kappa \mathrm{B}$ is suppressed. Induction of $\mathrm{I} \kappa \mathrm{B} \alpha$ expression can be seen as one of the mechanisms that contribute to the anti-inflammatory activities of PPAR $\alpha$ activators. It was also reported that pharmacologically activated PPAR $\alpha$ was capable to sequestrate the coactivator glucocorticoid receptor-interacting protein-1/transcriptional intermediary factor-2 (GRIP1/TIF2), leading to a reduced activity of the proinflammatory transcription factor CAATT/enhancer binding proteins $(\mathrm{C} / \mathrm{EBP})$ that ultimately cannot anymore transactivate the fibrinogen- $\beta$ gene in liver [129]. By virtue of their anti-inflammatory abilities, glucocorticoids are among the most commonly prescribed medications for the treatment of acute and chronic inflammatory diseases. Simultaneous activation of PPAR $\alpha$ and glucocorticoid receptor alpha (GR $\alpha$ ) enhances transrepression of NF- $\kappa \mathrm{B}$-driven gene expression and additively represses proinflammatory cytokine production [130]. This finding paves the road for new approaches for the treatment of inflammatory diseases where the additive effect of PPAR $\alpha$ and GR $\alpha$ activation could repress to a larger extent the inflammatory gene expression program.

3.1.3. Direct Upregulation of Anti-Inflammatory Genes by PPAR $\alpha$. PPAR $\alpha$ has been first described as a ligand-activated transcription factor across species and as such it directly upregulates a certain array of genes. In addition to downregulating expression of proinflammatory genes, PPAR $\alpha$ could therefore theoretically suppress the inflammatory response by direct upregulation of gene(s) with anti-inflammatory properties. Surprisingly, only a very limited number of inflammatory genes have been identified so far as direct PPAR $\alpha$ positive targets. Searching for novel direct PPAR $\alpha$ reguled genes in liver, we previously identified the Interleukin-1 receptor antagonist (IL1-Ra) gene as an additional mechanism for PPAR $\alpha$ to negatively regulate the APR in mouse liver [131]. It is noteworthy that upregulation of IL-1ra by PPAR $\alpha$ was conserved in human (HepG2 hepatoma cells and human monocyte/macrophage THP-1 cell line) supporting the notion that similar regulation likely occurs in humans $[131,132]$. Furthermore, using mice deficient in Ppara combined with pharmacological activation of PPAR $\alpha$ by the synthetic PPAR $\alpha$ agonists Wy, fenofibrate, or clofibrate, two different groups found that the liver expression of Vanin-1 (a glycosylphosphatidylinositol-linked membrane-associated pantetheinase that promotes the production of inflammatory mediators by intestinal epithelial cells) was directly regulated by PPAR $\alpha$ in mice $[118,133]$. Treatment of primary human hepatocytes or HepaRG cells (a cell line derived from a liver tumor of a female patient) with two different PPAR $\gamma$ agonists (RSG and troglitazone) also modulate the mRNA levels of Vanin-1 indicating that similar to PPAR $\alpha$, Vanin-1 could be regulated by PPAR $\gamma$ [134]. In vivo upregulation of Vanin-1 in the liver of mice by the di(2-ethylhexyl) phthalate (DEHP), a synthetic PPAR $\gamma$ ligand, has been also reported [135]. The question arises, why an anti-inflammatory transcription factor such as PPAR $\alpha$ would increase the expression of Vanin1 that rather promotes the inflammation process. At present, it is hard to reconcile the Wy-mediated upregulation of Vanin1 mRNA level in liver with the anti-inflammatory role of PPAR $\alpha$. Follow-up investigations are eagerly awaited to partly 
close this gap. Additionally, the group of S. Kersten also reported on the direct and critical role of human PPAR $\alpha$ in the hepatic regulation of the mannose-binding lectin $(M B L)$ gene, a soluble mediator of innate immunity [136]. Given that $M B L$ is an important player in complement cascade activation as part of the first-line host defense, the positive regulation $M B L$ fits within the role of PPAR $\alpha$ as important regulator of inflammation and innate immunity.

\subsection{Possible Role of PPAR $\beta / \delta$ in the Control of Inflamma-} tion Process in Liver. Similar to PPAR $\alpha$, the nuclear hormone receptor $P$ par $\beta / \delta$ is expressed in the liver and displays anti-inflammatory activities. For instance, mice fed the PPAR $\beta / \delta$ agonist L-165041 are partially protected from chronic ethanol-mediated hepatic injury and inflammation [137]. Yet, others have reported that PPAR $\beta / \delta$ would promote hepatic stellate cell proliferation during acute and chronic liver inflammation, favouring the onset of hepatic tissue injury [138]. Therefore, the role of PPAR $\beta / \delta$ in liver is not fully understood and it deserves further investigations. In an attempt to define the functional role of PPAR $\beta / \delta$ in the liver in mice, the group of S. Kersten and collaborators has used Affymetrix microarrays to compare the RNA populations of normally fed wild-type mice versus mice deficient in the $P \operatorname{par} \beta / \delta$ isoform [139]. $P$ par $\beta / \delta$ deletion was associated with enrichment of gene sets involved in various innate immunity and inflammation-related processes including natural killer cell-mediated cytotoxicity, antigen processing and presentation, and Toll-like receptor pathway. Significant higher expression of genes reflecting enhanced nuclear factor-kappa $\mathrm{B}(\mathrm{NF}-\kappa \mathrm{B})$ activity was found in $P$ par $\beta / \delta$ null mice [139]. Elevation of Kupffer cell (the resident macrophages in liver) marker gene expression was also observable. Enhanced expression of proinflammatory genes that are regulated by the NF- $\kappa \mathrm{B}$ signaling was also noted in Ppar $\beta / \delta$ null mice following administration of the prototypical liver-specific toxicant carbon tetrachloride (CCl4) administration [140]. Of interest, normal-diet fed mice infected by adenovirus overexpressing $P$ par $\beta / \delta$ in liver displayed reduced hepatic proinflammatory cytokines/chemokines (IL-1 $\beta$, Tnf- $\alpha$, Ifn- $\gamma$ (interferon- $\gamma$ ), and Mcp-1) gene expression by the activated proinflammatory M1 macrophages [141]. In contrast, markers for the alternative anti-inflammatory M2 macrophage activation such as $\mathrm{Mrcl}$ (mannose receptor, C type 1 , also known as Cluster of differentiation molecule-206, Cd206) and Mgl1 (galactosetype C-type lectin 1 , also referred to as Cluster of differentiation molecule-301, Cd301) were upregulated in the liver. Others have also reported that genetic deletion of $P$ par $\beta / \delta$ in mice impaired the alternative anti-inflammatory M2 activation of hepatic macrophages (Küppfer cells) [75]. It was concluded that $\operatorname{PPAR} \beta / \delta$ transcriptional signaling was required for the maintenance of alternative anti-inflammatory M2 activation of Kupffer cells in liver and for the decreased production of proinflammatory cytokines by the proinflammatory M1 macrophages. Curiously and in agreement with findings from Staels' group, these regulations were lost in mice fed a highfat diet, casting doubt on the real impact of PPAR $\beta / \delta$ in decreasing obesity-induced hepatic inflammation in mice [141].
Inflammatory processes are generally considered to follow the transition of steatosis (simple fatty liver) to nonalcoholic steatohepatitis (NASH) and are therefore regarded as a characteristic finding of NASH. Intriguingly, it was recently found that the PPAR $\beta / \delta$ agonist GW0742 could attenuate hepatic steatosis by reducing liver triglyceride content and proinflammatory cytokines liver gene expression on a type2 diabetic rat model [142]. However, this study did not aim at determining the impact of Kupffer cells on hepatic triglyceride storage and liver tissue inflammation. Consequently, unlike for PPAR $\alpha$, whether GW0742 involves some actions on Küppfer cells to prevent NASH is not documented.

Supporting further PPAR $\beta / \delta$ 's anti-inflammatory activity, treatment of mice with GW0742 or KD3010, two PPAR $\beta / \delta$ agonists, significantly reduced copper-induced proinflammatory and APR cytokines in liver of mice $[143,144]$. In contrast, blockade of the PPAR $\beta / \delta$ signaling pathway by the PPAR $\beta / \delta$ antagonist GSK0660 reverted copper-induced liver damages. Together, these findings support the notion that pharmacological activation of $\mathrm{PPAR} \beta / \delta$ could become an important tool in the management of liver inflammation.

\subsubsection{Humanized Mice for $h P P A R \beta / \delta$ : Role in Inflammation} Control in Liver. In order to investigate whether the human version of $\mathrm{PPAR} \beta / \delta$ also displays similar anti-inflammatory properties, a mouse model humanized for the PPAR $\beta / \delta$ isoform $(\mathrm{PPAR} \beta / \delta \mathrm{KI})$ was established in a C57BL/6J-stabilized genetic background [145]. Subsequent experiments have shed light on the role of human PPAR $\beta / \delta$ on liver inflammation in the context of diet-induced obesity in mice. Similar to $\operatorname{PPAR} \alpha$, pharmacological activation of $\operatorname{PPAR} \beta / \delta$ (both of human and mouse origins) by the synthetic GW0742 compound led to the comparable induction of the liver IL1$R a$ mRNA levels in WT and PPAR $\beta / \delta$ KI C57BL/6J mice. Moreover, it similarly decreased the gene expression of the proinflammatory cytokine Tnf- $\alpha$ and that of the APR proteins fibrinogen- $\alpha$ and fibrinogen- $\beta$ [145]. These observations support the notion that the mouse IL1-Ra gene is likely transcriptionally regulated by the multiple PPAR isotypes and that $\operatorname{PPAR} \beta / \delta$ plays anti-inflammatory functions in liver.

3.3. PPAR $\gamma$ : Role in the Control of Inflammation Process in Liver. A wealth of study has previously established a link between obesity and inflammation in the liver. Notably, excessive neutral lipids (triglycerides) accumulation in the liver can first lead to steatosis that may progress to steatohepatitis and ultimately to cirrhosis. In an effort to selectively study the functional role of liver PPAR $\gamma$ in obesity-induced hepatic inflammation, mice deleted of Ppary in hepatocytes using the cell type-specific gene-knockout technology were recently established $[146,147]$. While these mutant mice were protected against high-fat diet-induced hepatic steatosis, the number of liver inflammatory foci and the concentration of circulating inflammatory markers such as TNF- $\alpha$ and MCP1 were similar as to control mice. These data argue against a predominant role of the liver form of PPAR $\gamma$ in controlling proinflammatory cytokine gene expression in the context of obesity-induced inflammation. 
Many of the effects of TZDs are independent of PPAR $\gamma$ [148]. Supporting this notion, 15 -deoxy- $\Delta 12,14$-prostaglandin J2 (15d-PGJ2), a natural PPAR $\gamma$ agonist, was found to reduce the recruitment of bone marrow-derived monocyte/macrophages (BMDM) in the liver of mice suffering from cholestasis-induced hepatic inflammation [149]. The suppression of BMDM migration did not result from the direct activation of PPAR $\gamma$ because the inhibitory effect of $15 \mathrm{~d}-\mathrm{PGJ} 2$ on BMDM migration was not affected by the pharmacological antagonization of PPAR $\gamma$. Rather, 15d-PGJ2 reduced BMDM migration through ROS formation. Therefore, it should be acknowledged that some of the effects of TZDs on the inflammation process are independent of PPAR $\gamma$.

\section{PPARs and the APR across Species}

The complex series of reactions initiated in response to infection and inflammation, trauma, burns, ischemic necrosis, and malignant tumors is called the APR. It is present in all animal species and constitutes a core component of the innate immune system. These alterations are mostly mediated by proinflammatory cytokines, and if prolonged, they contribute to a variety of ailments such as dyslipidemia, atherogenesis, diabetes, mitochondrial dysfunction, and muscle mass loss. Interconnections between APR and PPARs are illustrated by the reduction of PPAR expression in response to bacterial LPS exposure in numerous tissues such as liver, heart, kidney, and WAT [150-152]. This observation actually extends to most of type II Nuclear Hormone Receptors (NHRs) [153-155]. The prevalently accepted anti-inflammatory role for PPARs suggested that their agonists may be able to counterbalance APR-induced inflammation. In particular, the protective roles of PPARs were evaluated in response to endotoxemia induced by Escherichia coli LPS.

4.1. PPAR $\alpha$ and the APR. Regarding PPAR $\alpha$, treating mice model of endotoxemia with fenofibrate or Wy surprisingly elevated TNF- $\alpha$ levels in plasma [156]. This elevation was not observed in Ppara knockout mice, further establishing a functional role of PPAR $\alpha$ in mediating this effect of LPS [157]. Furthermore, some authors reported that C57BL/6 mice injected intraperitoneally with $100 \mu \mathrm{g}$ of LPS (Escherichia coli LPS, serotype 055:B5) displayed a marked reduction in Cyp4a10 (cytochrome P450, family 4, subfamily a, polypeptide 10) mRNA levels in the kidney [158]. Intriguingly, LPS-mediated reduction of Cyp4a10 expression was still observable in the kidneys of Ppar $\alpha$-deficient mice. This finding suggests that mouse PPAR $\alpha$ does not trigger the effects of LPS on Cyp4a10 expression in the kidney [158]. Surprisingly, others found that injection of purified LPS (Escherichia coli LPS, serotype 0127:B8) in mice was inducing cytochrome Cyp4a10 and Cyp4a14 (cytochrome P450, family 4, subfamily a, polypeptide 14) expression in kidney, in a PPAR $\alpha$-dependent manner [159]. Downregulation of Cyp2a5, Cyp2c29, and Cyp3a11 by LPS was also comparatively reduced in Ppar $\alpha$ null mice, suggesting that PPAR $\alpha$ is somehow required for LPS-mediated gene regulation and could serve the purpose of LPS-mediated inflammation [159].
A profound role of PPAR $\alpha$ in counteracting inflammation during APR is also illustrated by the fact that wild-type C57BL/6 mice injected intraperitoneally with proinflammatory cytokines such as TNF- $\alpha$ and IL-1 $\beta$ (two potent inducers of APR) display a significant reduction in hepatic mRNA levels of Ppard and its obligate partner Rxr [155]. Similar results were also obtained using the human hepatoma Нер3B cell line; these data are in agreement with those reported by Stienstra and colleagues who recently disentangled the molecular mechanisms responsible for this reduction in Ppara mRNA levels [160]. Notably, further analysis revealed that the DNA binding of the heterodimer PPAR $\alpha / \mathrm{RXR} \alpha$ to cognate peroxisome proliferator-responsive elements was significantly reduced [155]. This interesting piece of data explains, at least partially, why the expression of well-known Ppar $\alpha$-regulated transcripts is also concomitantly reduced [155]. Thus, by downregulating Ppar $\alpha$ expression and PPAR $\alpha$ activity in liver, LPS challenge may limit fatty acid $\beta$ oxidation. As a consequence, LPS would favor a metabolic shift in fatty acid metabolism by promoting their esterification and accumulation in the liver, ultimately leading to sepsis-induced hypertriglyceridemia.

In humans, it was recently shown that fenofibrate did not perform better than placebo in a cardiometabolic inflammation model where healthy adults were treated with LPS [161]. However, several observations also indicated that PPAR $\alpha$ had beneficial effects against endotoxemia in humans. In spite of the relative low hepatic expression of PPAR $\alpha$ in human, its pharmacological activation using fenofibrate or bezafibrate has been shown to decrease plasma levels of several APR proteins that are normally increased during inflammatory conditions [162-164]. Furthermore, PPAR $\alpha$ activation by fenofibrate also prevents myocardial dysfunction during endotoxemia in rats [165].

Another line of evidence connecting PPAR $\alpha$ to the control of inflammation gene expression came with the use of a liver-restricted Ppara expression mouse model that was treated with bacterial LPS [166]. Using mice deficient in Ppard in all tissues except the liver, a specific liver action of PPAR $\alpha$ was highlighted because the hepatic expression and circulating levels of proinflammatory cytokines were comparatively lower in the mutant animals [166]. These findings support the notion that PPAR $\alpha$ readily reduces the stimulation of the acute phase response (APR).

Hence, while PPAR $\alpha$ is likely a factor playing a determinant role in the control of hepatic inflammation, its ability to control APR still deserves to be clearly unraveled.

4.2. $P P A R \beta / \delta$ and the $A P R$. Information on the role of $\operatorname{PPAR} \beta / \delta$ in the pathophysiology of sepsis-induced organ dysfunction and injury still remain fragmentary at the moment. In an effort to better investigate the role of $\mathrm{PPAR} \beta / \delta$ in murine model of LPS-induced sepsis, WT and $P$ par $\beta / \delta$-deficient mice-previously subjected to LPS, were given the selective PPAR $\beta / \delta$ ligand (GW0742). Notably, GW0742 attenuated the degree of LPS-induced pulmonary inflammation, as well as cardiac and renal dysfunction [156, 167]. In further support of a role of PPAR $\beta / \delta$ in endotoxemia, LPS-treated WT and $P$ par $\beta / \delta$-deficient mice were also given 
GSK0660 (a synthetic PPAR $\beta / \delta$ antagonist). Interestingly, most of the beneficial effects of GW0742 on the reduction of the septic shock was abolished [167]. PPAR $\beta / \delta$ may therefore represent an attractive method to counteract APR.

4.3. PPAR $\gamma$ and the APR. Similar to $\operatorname{PPAR} \alpha$, results obtained on the role of PPAR $\gamma$ led to inconsistent observations, at least in rodents. The protective roles of $\operatorname{PPAR} \gamma$ were particularly evaluated in response to endotoxemia induced by Escherichia coli LPS. It is worth recalling that RSG-induced activation of PPAR $\gamma$ in rats subjected to Escherichia coli LPS challenge alleviates LPS-mediated proinflammatory cytokine production in lungs inflammation models $[168,169]$. Other studies performed with male Wistar rats also concluded that the beneficial protection of the 15d-PGJ2 against the multiple organ failure caused by endotoxin was mediated partially through PPAR $\gamma$ [170]. It was proposed that once activated, PPAR $\gamma$ would attenuate LPS-induced release of high mobility group box 1 in blood, a well-known late proinflammatory mediator of sepsis [171]. However, it should be stressed that others found that pharmacological activation of the PPAR $\gamma$ isotype was not useful for the treatment of acute inflammation in lean or $d b / d b$ mice, raising doubts about the routine use of PPAR $\gamma$ agonists as anti-inflammatory agents in clinical applications [172]. The picture is even more complex because treating weaned pigs with RSG has been shown to be effective to protect them from LPS-induced intestinal damage, as the probable consequence of the inhibited production of intestinal proinflammatory mediators [173]. In conflict with these data, activation of PPAR $\gamma$ with RSG did not ameliorate and even worsened proinflammatory cytokine production in weaned pigs after Escherichia coli LPS challenge, casting doubts about the prevalently accepted anti-inflammatory role for PPAR $\gamma$ activation [174].

\section{PPARs in Inflammatory Bowel Disease (IBD)}

Characterized by an unrelenting destruction of the gut mucosa, the global prevalence rate of IBD is rising steadily. Ulcerative colitis and Crohn's disease are the two major forms of idiopathic IBD. These complex inflammatory diseases are usually developed in the second and third decades of life. Several players are involved in the onset of the disease among which not only different intestinal cells (intestinal epithelial cells, Paneth and goblet cells), second innate (macrophages, dendritic cells), and adaptive immune cells (lymphocytes), but also luminal bacteria. Collectively, scientific publications on IBD have established that the disease appears to involve maladaptive responses of the body to the intestinal flora, which also depends on individual genetic susceptibility.

Interestingly, all three PPAR isotypes are detected in the gastrointestinal tract. In rodents, Ppard is highly expressed in the proximal part of the small intestine (duodenum, jejunum) and colon but to a much lesser extent [175-177]. Expression of human PPAR $\alpha$ expression also peaks in the small intestine and is less in the colon $[118,175]$. Regarding mouse $P p a r \beta / \delta$, its expression is highest in the epithelial cells of the colon and much less in small intestine [176].
5.1. PPAR $\alpha$ in IBD. The role of PPAR $\alpha$ during colonic inflammation has been well documented in several studies. In a model of IBD in mice, proinflammatory cytokines formation such as TNF- $\alpha$ and IL- $1 \beta$ was significantly higher in colon samples from Ppar $\alpha$-deficient mice compared with those of WT mice [178]. Furthermore and as it could be expected, administration of Wy or fenofibrate to mice suffering from colitis decreased mortality as well as mRNA levels of proinflammatory cytokines (If $n \gamma, \operatorname{Tnf}-\alpha, I L-6, I L-1 \beta$, and Interleukin-17) in the distal colon leading to an overall delay in the onset of the disease [177]. Notably, the Wy lowering degree of colitis is PPAR $\alpha$ dependent [179]. Together, these results indicate that $\operatorname{PPAR} \alpha$ and $\operatorname{PPAR} \alpha$ ligands may play an important role in controlling colonic inflammation through the activation of PPAR $\alpha$.

5.2. $P P A R \beta / \delta$ in $I B D$. Concerning $P p a r \beta / \delta$, its deletion in mice resulted in exacerbated dextran sulfate sodium-induced colitis suggesting that this nuclear receptor could play a functional role against inflammatory colitis [180]. However, pharmacological activation of $\mathrm{PPAR} \beta / \delta$ did not protect against dextran sulfate sodium-induced colitis pointing towards a ligand-independent anti-inflammatory effect of $\operatorname{PPAR} \beta / \delta$. More studies need to be done in order to clarify its role in the reduction of IBD.

5.3. PPAR $\gamma$ in IBD. With respect to Ppary, its expression is restricted to the distal part of the intestine, especially caecum and colon $[83,176,181-184]$. Supporting a potential role of PPARs in IBD, colonic epithelial cells from ulcerative colitis patients express considerably lower levels of PPAR $\gamma$ [185]. In line with a role of PPAR $\gamma$ in the management of IBD, it is worth recalling that natural (such as conjugated linoleic acid) or synthetic PPAR $\gamma$ agonists provide effective treatments of colitis in rodent experimental models of the disease, but whether only PPAR $\gamma$-dependent mechanisms are involved remains an open issue [186]. Illustrating the close ties between PPAR $\gamma$ and IBD, mice with targeted disruption of the Ppary gene in intestinal epithelial cells displayed increased susceptibility to dextran sodium sulfate-induced colitis as well as higher mRNA levels of proinflammatory markers in the colon [187].

Notably, physical association of PPAR $\gamma$ with the transcription factor NF- $\kappa \mathrm{B}$ (p50-Rel A heterodimer) has also recently emerged as a novel crucial mechanism by which PPAR $\gamma$ could also limit inflammation in epithelial cells of the gut exposed to Bacteroides thetaiotaomicron, a chief component of commensal gut microflora and a prevalent anaerobe of the human intestine [188]. The newly formed PPAR $\gamma / \mathrm{NF}-\kappa \mathrm{B}$ p50-Rel A complex is rapidly exported from the nucleus resulting in the attenuation of NF- $\kappa \mathrm{B}$-mediated inflammation gene expression. Pharmacological modulation of this PPAR $\gamma$-dependent anti-inflammatory mechanism might be promising for fighting IBD.

Given the critical role of PPAR $\gamma$ in controlling the activity of NF- $\kappa \mathrm{B}$, it is surprising that none of the 22 human PPAR $\gamma$ genetic variants identified and tested by Mwinyi et al. was associated with IBD susceptibility or disease course; in view of these results, the question still comes up, if PPAR $\gamma$ is 
indeed a true modulating risk factor for IBD in humans [189].

Whereas Ppary is abundantly expressed in intestinal epithelial cells, it is also highly expressed in macrophages and T cells. Genetic rodent models where Ppary has been specifically invalidated in these cells have clearly indicated that PPAR $\gamma$ has protective effects on IBD [190-192]. Different mechanisms have been proposed so far however PPAR $\gamma$ antiinflammatory property appears to be central to its benefits. In intestinal epithelial cells, different reports established that the ability of PPAR $\gamma$ to alter TLR2 and TLR4 signaling is an important factor. This is an interesting observation given the role of luminal flora in IBD because TLR2 and TLR4 are receptors sensing microbe components such as LPS of gramnegative bacteria. In addition, goblet and Paneth cells are also implicated in IBD. Whereas Paneth cells have a protective role against Crohn's disease, goblet cells protect against colitis. Whether PPARs have a role in the function of these cells in IBD remains unclear at the moment.

\section{PPARs and Central Inflammation}

Diseases of the central nervous system (CNS) present a challenge for the development of new therapeutic agents. $P$ par $\gamma, P$ par $\alpha$, and $P$ par $\beta / \delta$ isoforms are expressed in the CNS at different levels, with $P$ par $\beta / \delta$ being the most abundant [86, 193-196].

6.1. PPAR $\alpha$ in Central Inflammation. In the CNS, the expression of Ppara has been described in brain and spinal cord $[193,196,197]$. To evaluate the possible role for PPAR $\alpha$ at the CNS level in mediating peripheral inflammation, the PPAR $\alpha$ agonist GW7647 was intracerebroventricularly injected in mice subjected to carrageenan-induced paw edema [198]. Interestingly, specific activation of central PPAR $\alpha$ controls inflammation in the spinal cord as well as in the periphery. It was concluded to the existence of a centrally mediated component for the anti-inflammatory effects of PPAR $\alpha$ agonists.

6.2. $P P A R \beta / \delta$ in Central Inflammation. There are several lines of evidence supporting that $\operatorname{PPAR} \beta / \delta$ serves a critical role in central inflammation. For instance, pharmacological activation of PPAR $\beta / \delta$ in rat aggregating brain cells cultures with the synthetic compound GW501516 decreased IFN $\gamma$ induced TNF $\alpha$ and INOS in a similar manner to what has been reported in isolated cultures [199]. Further supporting anti-inflammatory function for PPAR $\beta / \delta$, oral administration of the selective PPAR $\beta / \delta$ agonist GW0742 in a mouse of experimental autoimmune encephalomyelitis, reduced astroglial and microglial inflammatory activation as well as IL-1 $\beta$ levels in brain [200]. Activation of PPAR $\beta / \delta$ by the gemfibrozil molecule (an FDA-approved lipid-lowering drug) was also recently shown to be beneficial for the correction of bacterial LPS-mediated inflammation in human microglia, suggesting that central PPAR $\beta / \delta$ could be a novel interesting molecular target [201]. Follow-up studies have thereafter investigated if central PPAR $\beta / \delta$ could indeed play a role in the control of CNS inflammation. Supporting this hypothesis, it was found that mice with specific deletion of
Ppar $\beta / \delta$ in hypothalamic neurons exhibited elevated markers of hypothalamic inflammation such as IL- 6 and IL-1 $\beta$ [202]. Mutant mice fed a high-fat diet were also found to be resistant to further activation of hypothalamic inflammation. Central $\operatorname{PPAR} \beta / \delta$ appeared therefore as a critical transcription factor in the management of CNS inflammation and lipid accumulation [202].

6.3. PPAR $\gamma$ in Central Inflammation. Over the past few years, $\operatorname{PPAR} \gamma$ has been investigated for its action in ameliorating the development and progression of a number of CNS diseases. Because PPAR $\gamma$ agonists exhibit potent anti-inflammatory effects, the hypothesis was raised that they could display direct neuroprotective actions. Animal models of Alzheimer's disease or Parkinson's disease fed pioglitazone, a PPAR $\gamma$ agonist of the TZDs family, indeed displayed reduction in central inflammation and limited progression of the disease $[203,204]$. The availability of FDA-approved agonists of this receptor should facilitate the rapid translation of these findings into clinical trials for a number of CNS diseases.

\section{PPARs and Cardiac Inflammation}

Heart failure patients show elevated plasma levels of proinflammatory cytokines suggesting that chronic inflammation could play an important role in cardiac diseases such as the development of cardiac hypertrophy. Cardiac hypertrophic and inflammatory pathways are intrically connected because they both activate NF- $\kappa$ B. PPARs isoforms are all present in cardiac muscle cells of mice and rats even though the Ppary isoform is expressed at relatively low level [205].

7.1. PPAR $\alpha$ in Cardiac Inflammation. Not only is Ppara highly expressed in liver, it also plays a very important role in cardiac inflammation. One illuminating set of experiments carried out with hypertensive rats, fed or not the PPAR $\alpha$ activator fenofibrate, brings support to the notion that PPAR $\alpha$ is also capable to decrease expression of inflammatory genes associated with NF- $\kappa \mathrm{B}$ [206]. The anti-inflammatory effect of PPAR $\alpha$ was further supported by other studies conducted in hearts of WT and Ppara-deficient mice. Notably, deletion of Ppara had a marked effect on the expression of genes related to inflammation and immunity [207]. In the context of cardiac hypertrophy (which is characterized by induction of inflammatory pathways), mRNA levels of genes, known to be under the dependence of the transcription factor NF- $\kappa \mathrm{B}$ and therefore involved in inflammation and immunity, were decreased in neonatal rat cardiomyocytes treated with Wy or infected with adenoviruses overexpressing Ppar $[208,209]$. Together, these data point to a pivotal role of PPAR $\alpha$ in limiting the inflammatory response by transrepression of NF$\kappa \mathrm{B}$ in cardiomyocytes.

7.2. $P P A R \beta / \delta$ in Cardiac Inflammation. Interestingly, adenoviral-mediated overexpression of $P$ par $\beta / \delta$ in cultured neonatal rat cardiomyocytes substantially inhibited LPS-induced Tnf $\alpha$ expression [210]. In support of this result, pharmacological activation of the PPAR $\beta / \delta$ isotype with the GW501516 molecule prevented the proinflammatory profile induced by 
lipids in heart and human cardiac AC16 cells [211]. Global and cardiomyocyte-restricted deletion of $\operatorname{Ppar} \beta / \delta$ in mice has also definitively been instrumental in identifying $\operatorname{PPAR} \beta / \delta$ as a critical nuclear receptor controlling proinflammatory cytokines production in response to LPS treatment in cardiomyocytes [210, 211]. It was concluded that absence of $P \operatorname{par} \beta / \delta$ in cardiomyocytes further exaggerated LPS and lipid-induced proinflammatory cytokine production in heart.

7.3. PPAR $\gamma$ in Cardiac Inflammation. Besides metabolic effects, activation of PPAR $\gamma$ may also promote anti-inflammatory responses in heart. In agreement with this, mice infected by Trypanosoma cruzi (also known as Schizotrypanum cruzi) display intense inflammatory infection in cardiomyocytes. Supporting the assertion that PPAR $\gamma$ is a potent modulator of the inflammatory process, its selective activation by the 15d-PGJ2 inhibited the expression and activity of different inflammatory enzymes and proinflammatory cytokines in neonatal mouse Trypanosoma-cruzi-infected cardiomyocytes [212, 213].

\section{PPARs, Inflammation, and Endothelium}

8.1. PPAR $\alpha$ and the Control of Endothelial Inflammation. Pharmacological activation of endogenous PPAR $\alpha$ from porcine pulmonary-arterial endothelial cells or from human vascular endothelial cells with selective agonists reduced TNF- $\alpha$-mediated induction of inflammatory transcription factors $N F-\kappa B$ and $A P-1$ and expression of their target genes Vcam-1 and $I L-6$. This piece of data suggests that irrespective of the species, PPAR $\alpha$ is a molecular target that, once activated, reduces the proinflammatory phenotypes in endothelial cells [214, 215].

8.2. PPAR $\beta / \delta$ and the Control of Endothelial Inflammation. While the function of the $\operatorname{PPAR} \beta / \delta$ isotype largely remained an enigma until the last century, probably because of the lack of connection with evident clinical manifestations, knowledge concerning its impact on inflammation in endothelial cell has tremendously increased over the last few years. Supporting this statement, treatment of primary vascular endothelial EAhy926 cells with the Merck ligand $\mathrm{PPAR} \beta / \delta$ activator L-165041 suppressed TNF $\alpha$-induced adhesion molecule (such as VCAM-1 and MCP-1) through significant reduction in the nuclear translocation of NF$\kappa \mathrm{B}[216,217]$. Furthermore, treating human umbilical vein endothelial cells (HUVEC) with the same molecule reduced the levels of $\mathrm{C}$-reactive protein-mediated increase of Interleukin-6 (IL-6) and IL-8 [218]. Using the selective $\operatorname{PPAR} \beta / \delta$ agonist GW501516, others also reported the critical role of PPAR $\beta / \delta$ in the suppression of IL- $1 \beta$-induced VCAM1 and E-selectin expression in HUVECs [219]. At the molecular level, chromatin immunoprecipitation assays showed that ligand activation of PPAR $\beta / \delta$ in HUVECs switched the association of B cell lymphoma-6 (BCL-6), a transcription repressor and anti-inflammatory regulator, from PPAR $\beta / \delta$ to the vascular promoter of VCAM-1 [219]. Such an unconventional ligand-dependent transcriptional pathway in which $\operatorname{PPAR} \beta / \delta$ controls an inflammatory switch through its association and disassociation with the transcriptional repressor BCL-6 has been previously abundantly illustrated in macrophages foam cells [220].

Another way to limit the inflammatory response by the nuclear receptor PPAR $\beta / \delta$ in endothelial cells could partially involve its physical interaction with the Extracellular signalRegulated Kinases (ERK). Notably, ERK was found to serve as an anti-inflammatory signal that suppresses expression of NF- $\kappa \mathrm{B}$-dependent inflammatory genes by inhibiting IKK activity in endothelial cells [221]. Furthermore, ERK1, 2, and 5 enhance $\operatorname{PPAR} \beta / \delta$ transcriptional activity in $\mathrm{C} 2 \mathrm{C} 12$ murine myoblasts leading to a reduction in cytokine-mediated NF$\kappa \mathrm{B}$ activation $[67,222]$. Perhaps a similar molecular scenario could also take place in endothelial cells but it has not been documented yet. PPAR $\beta / \delta$ may therefore serve as a potent therapeutic target in inflammatory therapy.

8.3. PPARY and the Control of Endothelial Inflammation. The nuclear receptor Ppary is also expressed in vessel wall tissue including endothelial cells, which are, together with macrophages and smooth muscle cells, key players in atherosclerosis development $[223,224]$. A wealth of studies has previously shown that $\operatorname{PPAR} \gamma$ agonists can modulate the expression of many proinflammatory cytokines, chemokines, and adhesion molecules in endothelial cells $[225,226]$. However, some PPAR $\gamma$-independent effects have been reported for certain PPAR $\gamma$ agonists. Therefore, to circumvent the receptor-independent effect that individual PPAR $\gamma$ agonists may display, a constitutively ligand-independent active mutant form of PPAR $\gamma 1$ was delivered into human umbilical cord veins endothelial cells (HUVECs) [215]. Importantly, AP- 1 and NF- $\kappa$ B pathways were inhibited by the constitutively active form of PPAR $\gamma 1$ in endothelial cells, leading to the prevention of endothelial activation, leucocyte recruitment, and synthesis of proinflammatory adhesion molecules. Definitive evidence that PPAR $\gamma$ plays a functional role in regulating the inflammatory process in situ in endothelial cell comes with the establishment of LDL receptor-deficient mice deleted from Ppary especially in endothelial cells [227]. Lack of Ppary in primary endothelial cells leads to increased inflammation (as shown by the robust increased expression of $\operatorname{Tnf}-\alpha, M c p-$ 1 , and $I L-1 \beta$ ) in vessel wall of mutant mice treated with LPS or challenged with high-cholesterol diet. In agreement with these findings, others have also recently reported that the genetic deletion of Ppary in endothelium in mice was upregulating LPS signaling as the consequence of induction of NF- $\kappa$ B activity [228].

Together, these data reinforce the notion that the pharmacological activation of PPAR $\gamma$ is likely beneficial by limiting inflammation at the level of the endothelial cell as well.

In summary, all three PPARs isotypes display an antiinflammatory role by inhibiting the production of inflammatory cytokines in a large set of syndromes and diseases (Figure 2).

\section{Dairy Cattle and Mastitis: PPAR Modulators as Future Promising Treatment?}

In livestock species in general, data describing the use of synthetic PPAR agonists are very limited. Considering the 


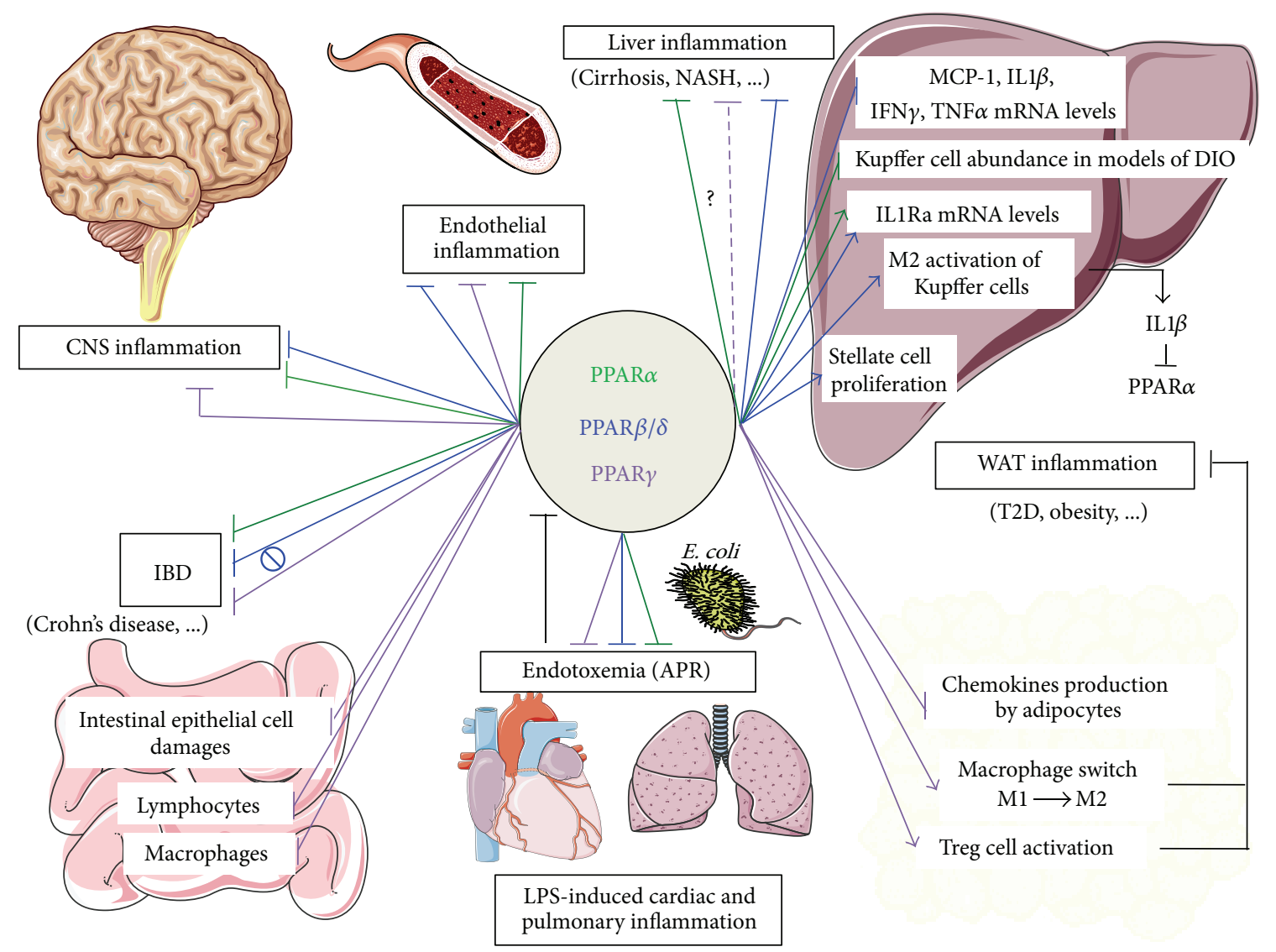

FIGURE 2: Representative illustration of PPAR main targets in inflammatory diseases. PPAR $\alpha$ mostly displays anti-inflammatory properties in the context of liver inflammation. Its reported liver targets are hepatocytes and Küppfer cells [131]. IL-1 $\beta$ produced by Küppfer cells potently suppresses Ppar $\alpha$ expression and activity via NF- $\kappa$ B-dependent inhibition of PPAR $\alpha$ promoter activity [160]. Besides downregulating gene expression of proinflammatory mediators such as Mcp-1, Tnf- $\alpha$, Ifn- $\gamma, I L-1 \beta$, and PPAR $\alpha$ also directly controls expression of IL1-ra in liver $[131,163]$. Küppfer cell activation is also dependent on PPAR $\beta / \delta$, which also targets stellate cells and therefore prevents liver fibrosis $[75,138]$. In addition, PPAR $\beta / \delta$ has well-established anti-inflammatory properties in diseases associated with CNS inflammation. In CNS, PPAR $\beta / \delta$ has also proven anti-inflammatory properties in neurons, glial cells, and astrocytes [200-202]. PPAR $\gamma$ anti-inflammatory properties are mainly illustrated in T2D and IBD. PPAR $\gamma$ serves as the molecular target of the insulin-sensitizing TZD drugs and plays a key role in T2D, adipogenesis and obesity. In WAT, mature adipocytes, Treg cells and macrophages have been identified as key cellular targets for PPAR $\gamma$ $[66,75,116,117]$. Macrophage-specific deletion of PPAR $\gamma$ leads to specific reduction in alternatively activated macrophages (M2 state) in WAT leading to local inflammation [110]. Moreover, Treg-cell-specific deletion of Ppar $\gamma$ was shown to reduce the abundance of Treg cells in WAT resulting in the increase of WAT infiltration by proinflammatory macrophages (M1) and monocytes [116, 117]. In IBD, PPAR $\gamma$ acts in intestinal epithelial cells, macrophages and lymphocytes [190-192]. Note that endotoxemia represses the mRNA expression level of Ppars (see black bar) [150-155]. Furthermore, multiple lines of evidence indicated that PPAR $\gamma$ is very important in endothelial cells, because it inhibits the in situ production of proinflammatory molecules such as vascular adhesion molecule-1 (VCAM-1), intercellular adhesion molecule-1 (ICAM-1) and MCP-1 [215, 223-228]. Similar conclusions were also drawn for the PPAR $\alpha$ and PPAR $\beta / \delta$ isotypes [214, 216-220]. Finally, PPARs display protective effets against endotoxemia $[166,167,169,236]$. NASH: nonalcoholic steatoHepatitis; T2D: type-2 diabetes; CNS: central nervous system; Treg cells: Foxp $3^{+} \mathrm{CD}^{+}$regulatory T cells; DIO: diet-induced-obesity; APR: acute phase response; green lines: action of PPAR $\alpha$; blue lines: action of PPAR $\beta / \delta$; purple lines: action of PPAR $\gamma$; ?: Some PPAR $\gamma$-independent effects of PPAR $\gamma$ activators have been proposed [146, 147]; Ø: pharmacological activation of PPAR $\beta / \delta$ did not protect against dextran sulfate sodium-induced colitis pointing towards a ligand-independent anti-inflammatory effect of PPAR $\beta / \delta[180]$.

high-amino acid identities ranging from 95 to $98 \%$ for PPARs proteins in all species, one can think that bovine and porcine PPARs could also be targeted with existing synthetic PPAR agonists [229]. On the other hand, because only a minor overlap between the Wy-regulated genes from mouse and human primary hepatocytes was found and since PPRE are not fundamentally conserved along species, we have to admit that activation of PPARs does not necessarily activate the same array of genes in one species versus another $[60,61]$.

One of the most common diseases in dairy cattle in the world is mastitis, which can be defined as an inflammation of the mammary gland tissue, resulting from the introduction and multiplication of pathogenic microorganisms. Mastitis 
is one of the most important health problems and is very costly for the dairy industry [230]. While treatment is possible with long-acting antibiotics, farmers have to wait until drug residues have left the cow's system before milk from such cows becomes again marketable. Several main causative bacteria that include Escherichia coli are responsible for the induction of inflammation of the udder tissue in dairy cattle. We have illustrated above that PPAR $\gamma$ activation, which typically results in the downregulation of inflammatory response, is suggested to be beneficial in inflammatory diseases not only in humans, but also in rats and pigs. We now question and discuss whether PPAR $\gamma$ activation could mitigate immunological stress of livestock, such as mastitis. As its function is to recognize pathogens that have not been encountered before, the innate immune system is the first line of defense against intramammary infection by bacteria [231]. It is generally accepted that emigration from the blood vessel of neutrophils (also known as polymorphonuclear neutrophil leucocytes) into the infected tissue, where they will deliver antimicrobial agents, is a hallmark of bacterial infection. Given that during the APR, reduction of the neutrophil flux into the mammary gland is believed to promote the incidence of severe Escherichia coli-induced mastitis, it could perhaps be envisioned to counterbalance this effect by treatment with existing PPAR $\gamma$ agonists [232]. Using two different mouse models of sepsis (cecal ligation and puncture as well as intraperitoneal injection of purified bacterial gram-negative LPS) it was rather shown that PPAR $\gamma$ inactivation with the GW9662 compound significantly (i) reversed the suppression of chemotaxis observed following LPS administration and (ii) increased recruitment of PMNs in the peritoneal cavity of mice subjected to cecal ligation and puncture [233]. Therefore, PPAR $\gamma$ displays two facets: once activated, it would dampen the massive production of proinflammatory cytokines in response to bacterial gramnegative LPS injection, by transrepressional mechanisms; at the same time, it would accentuate the suppression of chemotaxis further interfering with the recruitment of PMNs to the site of infection, two early key events for fighting against bacterial infection. Given that PPAR $\gamma$ is also a pivotal NHR involved in adipocyte differentiation and fat mass, modulating its activity could also affect fat depots important for meat quality. Therefore, pharmacological interventions in dairy cattle based on the use of PPAR $\gamma$ (anta) gonists may not offer an overall favorable therapeutic benefit, unless $\operatorname{PPAR} \gamma$ ability to control inflammation and interfere with PMN recruitment is disconnected in these pharmacological reagents. The recent generation of pigs, which display physiological and anatomical similarities with humans, in which one allele of the Ppary gene has been disrupted could be partly informative concerning the real involvement of PPAR $\gamma$ in the etiology of mastitis in livestocks [234].

Applications of PPAR $\alpha$ agonists could be of interest to decrease inflammation in the udder but since PPAR $\alpha$ signaling is decreased in bovine mammary tissue challenged with bacteria, and because fatty acid oxidation is under the dependence of PPAR $\alpha$ in the liver, the routine use of such molecules remains largely speculative [235].

\section{Concluding Remarks}

PPARs are lipid sensing transcription factors that were originally targeted in order to normalize metabolic issues. However, it also turned out that these NHRs were as well potently involved in switching off inflammation. Thanks to their respective and well conserved expression in numerous tissues amongst species, the prevalence of inflammatory diseases could be reduced by the use of a combination of different PPARs agonists. Quite surprisingly though, only a limited number of anti-inflammatory genes have been identified so far as direct and classical PPAR targets with a functional PPRE in genomic DNA, which could appear a bit puzzling at first glance. However, mechanisms involved in the anti-inflammatory properties of PPARs are broader than what might have been thought originally. Such properties are the reflect of a much elaborated transrepressional activity. The mechanisms behind this activity are currently being studied and remain more or less elusive at the moment. Therefore, it will be a major challenge for the future, in terms of therapeutic applications, to fully understand how these NHRs work and control inflammation. Compared to other anti-inflammatory strategies such as that involving glucocorticoids and its receptors, PPARs agonists may be responsible for limited drawbacks, yet their use also revealed controversial results in terms of efficacy and side effects.

\section{Acknowledgments}

This work was supported by the Institut National de la Santé et de la Recherche Médicale (INSERM, Centre de Recherches U866), the Conseil Régional de Bourgogne, the Université de Bourgogne, and a French Government Grant managed by the French National Research Agency under the program "Investissements d'Avenir" with reference ANR-11LABX-0021. D. Patsouris is supported by l'Agence Nationale pour la Recherche (ANR; ANR-09-RPDOC-018-01).

\section{References}

[1] S. Kersten, S. Mandard, P. Escher et al., "The peroxisome proliferator-activated receptor $\alpha$ regulates amino acid metabolism," FASEB Journal, vol. 15, no. 11, pp. 1971-1978, 2001.

[2] K. Nadra, S. I. Anghel, E. Joye et al., "Differentiation of trophoblast giant cells and their metabolic functions are dependent on peroxisome proliferator-activated receptor $\beta / \delta$," Molecular and Cellular Biology, vol. 26, no. 8, pp. 3266-3281, 2006.

[3] N. S. Tan, G. Icre, A. Montagner, B. Bordier-Ten Heggeler, W. Wahli, and L. Michalik, "The nuclear hormone receptor peroxisome proliferator-activated receptor $\beta / \delta$ potentiates cell chemotactism, polarization, and migration," Molecular and Cellular Biology, vol. 27, no. 20, pp. 7161-7175, 2007.

[4] R. Genolet, S. Kersten, O. Braissant et al., "Promoter rearrangements cause species-specific hepatic regulation of the glyoxylate reductase/hydroxypyruvate reductase gene by the peroxisome proliferator-activated receptor $\alpha$," Journal of Biological Chemistry, vol. 280, no. 25, pp. 24143-24152, 2005.

[5] S. Mandard, R. Stienstra, P. Escher et al., "Glycogen synthase 2 is a novel target gene of peroxisome proliferator-activated 
receptors," Cellular and Molecular Life Sciences, vol. 64, no. 9, pp. 1145-1157, 2007.

[6] J. Chamouton, F. Hansmannel, J. A. Bonzo et al., "The peroxisomal 3-keto-acyl-CoA thiolase B gene expression is under the dual control of PPAR and HNF4 in the liver," PPAR Research, vol. 2010, Article ID 352957, 17 pages, 2010.

[7] A. IJpenberg, E. Jeannin, W. Wahli, and B. Desvergne, "Polarity and specific sequence requirements of peroxisome proliferatoractivated receptor (PPAR)/retinoid X receptor heterodimer binding to DNA. A functional analysis of the malic enzyme gene PPAR response element," Journal of Biological Chemistry, vol. 272, no. 32, pp. 20108-20117, 1997.

[8] N. Di-Po, N. S. Tan, L. Michalik, W. Wahli, and B. Desvergne, "Antiapoptotic role of PPAR $\beta$ in keratinocytes via transcriptional control of the Aktl signaling pathway," Molecular Cell, vol. 10, no. 4, pp. 721-733, 2002.

[9] N. S. Tan, L. Michalik, B. Desvergne, and W. Wahli, "Multiple expression control mechanisms of peroxisome proliferatoractivated receptors and their target genes," Journal of Steroid Biochemistry and Molecular Biology, vol. 93, no. 2-5, pp. 99-105, 2005.

[10] N. S. Tan, L. Michalik, N. Noy et al., "Critical roles of PPAR $\beta / \delta$ in keratinocyte response to inflammation," Genes and Development, vol. 15, no. 24, pp. 3263-3277, 2001.

[11] P. R. Devchand, H. Keller, J. M. Peters, M. Vazquez, F. J. Gonzalez, and W. Wahli, "The PPAR $\alpha$-leukotriene B4 pathway to inflammation control," Nature, vol. 384 , no. 6604 , pp. 39-43, 1996.

[12] I. Issemann and S. Green, "Activation of a member of the steroid hormone receptor superfamily by peroxisome proliferators," Nature, vol. 347, no. 6294, pp. 645-650, 1990.

[13] C. Dreyer, G. Krey, H. Keller, F. Givel, G. Helftenbein, and W. Wahli, "Control of the peroxisomal $\beta$-oxidation pathway by a novel family of nuclear hormone receptors," Cell, vol. 68 , no. 5 , pp. 879-887, 1992.

[14] A. Schmidt, N. Endo, S. J. Rutledge, R. Vogel, D. Shinar, and G. A. Rodan, "Identification of a new member of the steroid hormone receptor superfamily that is activated by a peroxisome proliferator and fatty acids," Molecular Endocrinology, vol. 6, no. 10, pp. 1634-1641, 1992.

[15] E. Z. Amri, F. Bonino, G. Ailhaud, N. A. Abumrad, and P. A. Grimaldi, "Cloning of a protein that mediates transcriptional effects of fatty acids in preadipocytes. Homology to peroxisome proliferator-activated receptors," Journal of Biological Chemistry, vol. 270, no. 5, pp. 2367-2371, 1995.

[16] Y. Zhu, K. Alvares, Q. Huang, M. S. Rao, and J. K. Reddy, "Cloning of a new member of the peroxisome proliferator-activated receptor gene family from mouse liver," Journal of Biological Chemistry, vol. 268, no. 36, pp. 26817-26820, 1993.

[17] F. Chen, S. W. Law, and B. W. O'Malley, "Identification of two mPPAR related receptors and evidence for the existence of five subfamily members," Biochemical and Biophysical Research Communications, vol. 196, no. 2, pp. 671-677, 1993.

[18] P. Tontonoz, E. Hu, R. A. Graves, A. I. Budavari, and B. M. Spiegelman, "mPPAR $\gamma 2$ : tissue-specific regulator of an adipocyte enhancer," Genes and Development, vol. 8, no. 10, pp. 12241234, 1994.

[19] M. Nagasawa, T. Ide, M. Suzuki et al., "Pharmacological characterization of a human-specific peroxisome proliferater-activated receptor $\alpha(\mathrm{PPAR} \alpha)$ agonist in dogs," Biochemical Pharmacology, vol. 67, no. 11, pp. 2057-2069, 2004.
[20] D. Auboeuf, J. Rieusset, L. Fajas et al., "Tissue distribution and quantification of the expression of mRNAs of peroxisome proliferator-activated receptors and liver X receptor- $\alpha$ in humans: no alteration in adipose tissue of obese and NIDDM patients," Diabetes, vol. 46, no. 8, pp. 1319-1327, 1997.

[21] C. Aperlo, "cDNA cloning and characterization of the transcriptional activities of the hamster peroxisome proliferatoractivated receptor haPPAR $\gamma$," Gene, vol. 162, no. 2, pp. 297-302, 1995.

[22] T. Sher, H. F. Yi, O. W. McBride, and F. J. Gonzalez, "cDNA cloning, chromosomal mapping, and functional characterization of the human peroxisome proliferator activated receptor," Biochemistry, vol. 32, no. 21, pp. 5598-5604, 1993.

[23] C. Diot and M. Douaire, "Characterization of a cDNA sequence encoding the peroxisome proliferator activated receptor $\alpha$ in the chicken," Poultry Science, vol. 78, no. 8, pp. 1198-1202, 1999.

[24] S. A. Kliewer, B. M. Forman, B. Blumberg et al., "Differential expression and activation of a family of murine peroxisome proliferator-activated receptors," Proceedings of the National Academy of Sciences of the United States of America, vol. 91, no. 15, pp. 7355-7359, 1994.

[25] A. Ibabe, M. Grabenbauer, E. Baumgart, D. H. Fahimi, and M. P. Cajaraville, "Expression of peroxisome proliferator-activated receptors in zebrafish (Danio rerio)," Histochemistry and Cell Biology, vol. 118, no. 3, pp. 231-239, 2002.

[26] A. Ibabe, M. Grabenbauer, E. Baumgart, A. Völkl, H. D. Fahimi, and M. P. Cajaraville, "Expression of peroxisome proliferatoractivated receptors in the liver of gray mullet (Mugil cephalus)," Acta Histochemica, vol. 106, no. 1, pp. 11-19, 2004.

[27] M. J. Leaver, E. Boukouvala, E. Antonopoulou et al., "Three peroxisome proliferator-activated receptor isotypes from each of two species of marine fish," Endocrinology, vol. 146, no. 7, pp. 3150-3162, 2005.

[28] E. Boukouvala, E. Antonopoulou, L. Favre-Krey et al., "Molecular characterization of three peroxisome proliferator-activated receptors from the sea bass (Dicentrarchus labrax)," Lipids, vol. 39, no. 11, pp. 1085-1092, 2004.

[29] M. J. Leaver, M. T. Ezaz, S. Fontagne, D. R. Tocher, E. Boukouvala, and G. Krey, "Multiple peroxisome proliferator-activated receptor $\beta$ subtypes from Atlantic salmon (Salmo salar)," Journal of Molecular Endocrinology, vol. 38, no. 3-4, pp. 391-400, 2007.

[30] J. D. Tugwood, P. R. Holden, N. H. James, R. A. Prince, and R. A. Roberts, "A peroxisome proliferator-activated receptor-alpha $(\mathrm{PPAR} \alpha)$ cDNA cloned from guinea-pig liver encodes a protein wit h similar properties to the mouse PPAR $\alpha$ : implications for species differences in responses to peroxisome proliferators," Archives of Toxicology, vol. 72, no. 3, pp. 169-177, 1998.

[31] M. L. Tsai, H. Y. Chen, M. C. Tseng, and R. C. Chang, "Cloning of peroxisome proliferators activated receptors in the cobia (Rachycentron canadum) and their expression at different lifecycle stages under cage aquaculture," Gene, vol. 425, no. 1-2, pp. 69-78, 2008

[32] N. Nishii, M. Takasu, O. K. Soe et al., "Cloning, expression and investigation for polymorphisms of canine peroxisome proliferator-activated receptors," Comparative Biochemistry and Physiology B, vol. 147, no. 4, pp. 690-697, 2007.

[33] S. He, X.-F. Liang, C.-M. Qu, W. Huang, W.-B. Zhang, and K.S. Mai, "Identification, organ expression and ligand-dependent expression levels of peroxisome proliferator activated receptors in grass carp (Ctenopharyngodon idella)," Comparative Biochemistry and Physiology, vol. 155, no. 2, pp. 381-388, 2012. 
[34] H. Meng, H. Li, and X. Y. Wang, "Cloning and sequence analysis of cDNA encoding PPAR from goose," Yi Chuan, vol. 26, no. 4, pp. $469-472,2004$.

[35] H. Mano, C. Kimura, Y. Fujisawa et al., "Cloning and function of rabbit peroxisome proliferator-activated receptor $\delta / \beta$ in mature osteoclasts," Journal of Biological Chemistry, vol. 275, no. 11, pp. 8126-8132, 2000.

[36] E. Grindflek, H. Sundvold, H. Klungland, and S. Lien, "Characterisation of porcine peroxisome proliferator-activated receptors $\gamma 1$ and $\gamma 2$ : detection of breed and age differences in gene expression," Biochemical and Biophysical Research Communications, vol. 249, no. 3, pp. 713-718, 1998.

[37] K. G. Lambe and J. D. Tugwood, "A human peroxisome-proliferator-activated receptor- $\gamma$ is activated by inducers of adipogenesis, including thiazalidinedione drugs," European Journal of Biochemistry, vol. 239, no. 1, pp. 1-7, 1996.

[38] T. Omi, B. Brenig, S. Spilar, S. Iwamoto, G. Stranzinger, and S. Neuenschwander, "Identification and characterization of novel peroxisome proliferator-activated receptor-gamma (PPAR- $\gamma$ ) transcriptional variants in pig and human," Journal of Animal Breeding and Genetics, Supplement, vol. 122, no. 1, pp. 45-53, 2005.

[39] J. Zhou, K. M. Wilson, and J. D. Medh, "Genetic analysis of four novel peroxisome proliferator activated receptor- $\gamma$ splice variants in monkey macrophages," Biochemical and Biophysical Research Communications, vol. 293, no. 1, pp. 274-283, 2002.

[40] H. Sundvold, E. Grindflek, and S. Lien, "Tissue distribution of porcine peroxisome proliferator-activated receptor $\alpha$ : detection of an alternatively spliced mRNA," Gene, vol. 273, no. 1, pp. 105113, 2001.

[41] J. C. Hanselman, M. V. Vartanian, B. P. Koester et al., "Expression of the mRNA encoding truncated PPAR $\alpha$ does not correlate with hepatic insensitivity to peroxisome proliferators," Molecular and Cellular Biochemistry, vol. 217, no. 1-2, pp. 91-97, 2001.

[42] K. L. Houseknecht, C. A. Bidwell, C. P. Portocarrero, and M. E. Spurlock, "Expression and cDNA cloning of porcine peroxisome proliferator-activated receptor gamma (PPAR $\gamma)$," Gene, vol. 225, no. 1-2, pp. 89-96, 1998.

[43] D. A. Winegar, P. J. Brown, W. O. Wilkison et al., "Effects of fenofibrate on lipid parameters in obese rhesus monkeys," Journal of Lipid Research, vol. 42, no. 10, pp. 1543-1551, 2001.

[44] H. Escriva, R. Safi, C. Hänni et al., "Ligand binding was acquired during evolution of nuclear receptors," Proceedings of the National Academy of Sciences of the United States of America, vol. 94, no. 13, pp. 6803-6808, 1997.

[45] H. Oku and T. Umino, "Molecular characterization of peroxisome proliferator-activated receptors (PPARs) and their gene expression in the differentiating adipocytes of red sea bream Pagrus major," Comparative Biochemistry and Physiology B, vol. 151, no. 3, pp. 268-277, 2008.

[46] S. F. Eddy, P. Morin, and K. B. Storey, "Cloning and expression of PPAR $\gamma$ and PGC- $1 \alpha$ from the hibernating ground squirrel, Spermophilus tridecemlineatus," Molecular and Cellular Biochemistry, vol. 269, no. 1, pp. 175-182, 2005.

[47] M. E. Greene, B. Blumberg, O. W. McBride et al., "Isolation of the human peroxisome proliferator activated receptor gamma cDNA: expression in hematopoietic cells and chromosomal mapping," Gene Expression, vol. 4, no. 4-5, pp. 281-299, 1995.
[48] D. Raingeard, I. Cancio, and M. P. Cajaraville, "Cloning and expression pattern of peroxisome proliferator-activated receptor $\alpha$ in the thicklip grey mullet Chelon labrosus," Marine Environmental Research, vol. 62, no. 1, pp. S113-S117, 2006.

[49] Y. Chen, A. R. Jimenez, and J. D. Medh, "Identification and regulation of novel PPAR- $\gamma$ splice variants in human THP-1 macrophages," Biochimica et Biophysica Acta, vol. 1759, no. 1-2, pp. 3243, 2006.

[50] E. E. Girroir, H. E. Hollingshead, P. He, B. Zhu, G. H. Perdew, and J. M. Peters, "Quantitative expression patterns of peroxisome proliferator-activated receptor- $\beta / \delta(\operatorname{PPAR} \beta / \delta)$ protein in mice," Biochemical and Biophysical Research Communications, vol. 371, no. 3, pp. 456-461, 2008.

[51] I. Takada, M. Kobayashi, and I. Takada, "Structural features and transcriptional activity of chicken PPARs $(\alpha, \beta$, and $\gamma)$," PPAR Research, vol. 2013, Article ID 186312, 7 pages, 2013.

[52] J. N. Feige, L. Gelman, C. Tudor, Y. Engelborghs, W. Wahli, and B. Desvergne, "Fluorescence imaging reveals the nuclear behavior of peroxisome proliferator-activated receptor/retinoid $\mathrm{X}$ receptor heterodimers in the absence and presence of ligand," Journal of Biological Chemistry, vol. 280, no. 18, pp. 17880-17890, 2005.

[53] A. IJpenberg, E. Jeannin, W. Wahli, and B. Desvergne, "Polarity and specific sequence requirements of peroxisome proliferatoractivated receptor (PPAR)/retinoid X receptor heterodimer binding to DNA. A functional analysis of the malic enzyme gene PPAR response element," Journal of Biological Chemistry, vol. 272, no. 32, pp. 20108-20117, 1997.

[54] S. Mandard, F. Zandbergen, S. T. Nguan et al., "The direct peroxisome proliferator-activated receptor target fasting-induced adipose factor (FIAF/PGAR/ANGPTL4) is present in blood plasma as a truncated protein that is increased by fenofibrate treatment," Journal of Biological Chemistry, vol. 279, no. 33, pp. 34411-34420, 2004.

[55] T. Helledie, L. Grøntved, S. S. Jensen et al., "The gene encoding the acyl-CoA-binding protein is activated by peroxisome proliferator-activated receptor $\gamma$ through an intronic response element functionally conserved between humans and rodents," Journal of Biological Chemistry, vol. 277, no. 30, pp. 2682126830, 2002.

[56] T. Degenhardt, M. Matilainen, K. H. Herzig, T. W. Dunlop, and C. Carlberg, "The insulin-like growth factor-binding protein 1 gene is a primary target of peroxisome proliferator-activated receptors," Journal of Biological Chemistry, vol. 281, no. 51, pp. 39607-39619, 2006.

[57] R. Nielsen, T. Å. Pedersen, D. Hagenbeek et al., "Genome-wide profiling of PPAR $\gamma:$ RXR and RNA polymerase II occupancy reveals temporal activation of distinct metabolic pathways and changes in RXR dimer composition during adipogenesis," Genes and Development, vol. 22, no. 21, pp. 2953-2967, 2008.

[58] M. Boergesen, T. Å. Pedersen, B. Gross et al., "Genome-wide profiling of liver $\mathrm{X}$ receptor, retinoid $\mathrm{X}$ receptor, and peroxisome proliferator-activated receptor $\alpha$ in mouse liver reveals extensive sharing of binding sites," Molecular and Cellular Biology, vol. 32, no. 4, pp. 852-867, 2012.

[59] J. Auwerx, M. Beato, P. Chambon et al., "A unified nomenclature system for the nuclear receptor superfamily," Cell, vol. 97, no. 2, pp. 161-163, 1999.

[60] M. Heinäniemi, J. O. Uski, T. Degenhardt, and C. Carlberg, "Meta-analysis of primary target genes of peroxisome proliferator-activated receptors," Genome Biology, vol. 8, no. 7, article R147, 2007. 
[61] M. Rakhshandehroo, G. Hooiveld, M. Müller, and S. Kersten, "Comparative analysis of gene regulation by the transcription factor PPAR $\alpha$ between mouse and human," PLoS ONE, vol. 4, no. 8, Article ID e6796, 2009.

[62] A. Tsuchida, T. Yamauchi, S. Takekawa et al., "Peroxisome proliferator-activated receptor (PPAR) $\alpha$ activation increases adiponectin receptors and reduces obesity-related inflammation in adipose tissue: comparison of activation of PPAR $\alpha, \operatorname{PPAR} \gamma$, and their combination," Diabetes, vol. 54, no. 12, pp. 3358-3370, 2005.

[63] R. Stienstra, S. Mandard, D. Patsouris, C. Maass, S. Kersten, and M. Müller, "Peroxisome proliferator-activated receptor $\alpha$ protects against obesity-induced hepatic inflammation," Endocrinology, vol. 148, no. 6, pp. 2753-2763, 2007.

[64] T. Toyoda, Y. Kamei, H. Kato et al., "Effect of peroxisome proliferator-activated receptor- $\alpha$ ligands in the interaction between adipocytes and macrophages in obese adipose tissue," Obesity, vol. 16, no. 6, pp. 1199-1207, 2008.

[65] S. Mandard, F. Zandbergen, E. Van Straten et al., “The fastinginduced adipose factor/angiopoietin-like protein 4 is physically associated with lipoproteins and governs plasma lipid levels and adiposity," Journal of Biological Chemistry, vol. 281, no. 2, pp. 934-944, 2006.

[66] C. Marathe, M. N. Bradley, C. Hong et al., "Preserved glucose tolerance in high-fat-fed $\mathrm{C} 57 \mathrm{BL} / 6$ mice transplanted with PPAR $\gamma$-/-, PPAR $\delta$-/-, PPAR $\gamma \delta$-/-, or LXR $\alpha \beta$-/-bone marrow," Journal of Lipid Research, vol. 50, no. 2, pp. 214-224, 2009.

[67] R. Rodríguez-Calvo, L. Serrano, T. Coll et al., "Activation of peroxisome proliferator-activated receptor $\beta / \delta$ inhibits lipopolysaccharide-induced cytokine production in adipocytes by lowering nuclear factor- $\kappa \mathrm{B}$ activity via extracellular signal-related kinase 1/2," Diabetes, vol. 57, no. 8, pp. 2149-2157, 2008.

[68] S. M. Reilly and C. H. Lee, "PPAR $\delta$ as a therapeutic target in metabolic disease," FEBS Letters, vol. 582, no. 1, pp. 26-31, 2008.

[69] J. B. Hansen, H. Zhang, T. H. Rasmussen, R. K. Petersen, E. N. Flindt, and K. Kristiansen, "Peroxisome proliferator-activated receptor $\delta(\operatorname{PPAR} \delta)$-mediated regulation of preadipocyte proliferation and gene expression is dependent on cAMP signaling," Journal of Biological Chemistry, vol. 276, no. 5, pp. 3175-3182, 2001.

[70] Y. Barak, D. Liao, W. He et al., "Effects of peroxisome proliferator-activated receptor $\delta$ on placentation, adiposity, and colorectal cancer," Proceedings of the National Academy of Sciences of the United States of America, vol. 99, no. 1, pp. 303-308, 2002.

[71] G. D. Barish, V. A. Narkar, and R. M. Evans, "PPAR $\delta$ : a dagger in the heart of the metabolic syndrome," Journal of Clinical Investigation, vol. 116, no. 3, pp. 590-597, 2006.

[72] C.-H. Lee, P. Olson, A. Hevener et al., "PPAR $\delta$ regulates glucose metabolism and insulin sensitivity," Proceedings of the National Academy of Sciences of the United States of America, vol. 103, no. 9, pp. 3444-3449, 2006.

[73] T. Tanaka, J. Yamamoto, S. Iwasaki et al., "Activation of peroxisome proliferator-activated receptor $\delta$ induces fatty acid $\beta$-oxidation in skeletal muscle and attenuates metabolic syndrome," Proceedings of the National Academy of Sciences of the United States of America, vol. 100, no. 26, pp. 15924-15929, 2003.

[74] S. Luquet, J. Lopez-Soriano, D. Holst et al., "Peroxisome proliferator-activated receptor $\delta$ controls muscle development and oxidative capability," FASEB Journal, vol. 17, no. 15, pp. 22992301, 2003.
[75] J. I. Odegaard, R. R. Ricardo-Gonzalez, A. Red Eagle et al., "Alternative M2 activation of Kupffer cells by PPARdelta ameliorates obesity-induced insulin resistance," Cell Metabolism, vol. 7, no. 6, pp. 496-507, 2008.

[76] S. P. Weisberg, D. McCann, M. Desai, M. Rosenbaum, R. L. Leibel, and A. W. Ferrante, "Obesity is associated with macrophage accumulation in adipose tissue," Journal of Clinical Investigation, vol. 112, no. 12, pp. 1796-1808, 2003.

[77] H. Xu, G. T. Barnes, Q. Yang et al., "Chronic inflammation in fat plays a crucial role in the development of obesity-related insulin resistance," Journal of Clinical Investigation, vol. 112, no. 12, pp. 1821-1830, 2003.

[78] S. Gordon, "Alternative activation of macrophages," Nature Reviews Immunology, vol. 3, no. 1, pp. 23-35, 2003.

[79] K. Kang, S. M. Reilly, V. Karabacak et al., "Adipocyte-derived Th2 cytokines and myeloid PPARdelta regulate macrophage polarization and insulin sensitivity," Cell Metabolism, vol. 7, no. 6, pp. 485-495, 2008.

[80] G. H. Goossens, "The role of adipose tissue dysfunction in the pathogenesis of obesity-related insulin resistance," Physiology and Behavior, vol. 94, no. 2, pp. 206-218, 2008.

[81] H. Sundvold, A. Brzozowska, and S. Lien, "Characterisation of bovine peroxisome proliferator-activated receptors $\gamma 1$ and $\gamma 2$ : genetic mapping and differential expression of the two isoforms," Biochemical and Biophysical Research Communications, vol. 239, no. 3, pp. 857-861, 1997.

[82] H. Meng, H. Li, J. G. Zhao, and Z. L. Gu, "Differential expression of peroxisome proliferator-activated receptors alpha and gamma gene in various chicken tissues," Domestic Animal Endocrinology, vol. 28, no. 1, pp. 105-110, 2005.

[83] P. Escher, O. Braissant, S. Basu-Modak, L. Michalik, W. Wahli, and B. Desvergne, "Rat PPARs: quantitative analysis in adult rat tissues and regulation in fasting and refeeding," Endocrinology, vol. 142, no. 10, pp. 4195-4202, 2001.

[84] F. Zandbergen, S. Mandard, P. Escher et al., "The G0/G1 switch gene 2 is a novel PPAR target gene," Biochemical Journal, vol. 392, no. 2, pp. 313-324, 2005.

[85] R. Mukherjee, L. Jow, G. E. Croston, and J. R. Paterniti, "Identification, characterization, and tissue distribution of human peroxisome proliferator-activated receptor (PPAR) isoforms PPAR $\gamma 2$ versus PPAR $\gamma 1$ and activation with retinoid X receptor agonists and antagonists," Journal of Biological Chemistry, vol. 272, no. 12, pp. 8071-8076, 1997.

[86] O. Braissant, F. Foufelle, C. Scotto, M. Dauça, and W. Wahli, "Differential expression of peroxisome proliferator-activated receptors (PPARs): tissue distribution of PPAR- $\alpha,-\beta$, and $-\gamma$ in the adult rat," Endocrinology, vol. 137, no. 1, pp. 354-366, 1996.

[87] P. Tontonoz, E. Hu, and B. M. Spiegelman, "Stimulation of adipogenesis in fibroblasts by PPAR $\gamma 2$, a lipid-activated transcription factor," Cell, vol. 79, no. 7, pp. 1147-1156, 1994.

[88] R. P. Brun, P. Tontonoz, B. M. Forman et al., "Differential activation of adipogenesis by multiple PPAR isoforms," Genes and Development, vol. 10, no. 8, pp. 974-984, 1996.

[89] T. Imai, R. Takakuwa, S. Marchand et al., "Peroxisome proliferator-activated receptor $\gamma$ is required in mature white and brown adipocytes for their survival in the mouse," Proceedings of the National Academy of Sciences of the United States of America, vol. 101, no. 13, pp. 4543-4547, 2004.

[90] A. Chawla, K. D. Nguyen, and Y. P. S. Goh, "Macrophage-mediated inflammation in metabolic disease," Nature Reviews Immunology, vol. 11, no. 11, pp. 738-749, 2011. 
[91] J. Y. Kim, E. Van De Wall, M. Laplante et al., “Obesity-associated improvements in metabolic profile through expansion of adipose tissue," Journal of Clinical Investigation, vol. 117, no. 9, pp. 2621-2637, 2007.

[92] J. Xu, H. Morinaga, D. Oh et al., "GPR105 ablation prevents inflammation and improves insulin sensitivity in mice with diet-induced obesity," Journal of Immunology, vol. 189, no. 4, pp. 1992-1999, 2012.

[93] D. Y. Oh, S. Talukdar, E. J. Bae et al., "GPR120 is an omega-3 fatty acid receptor mediating potent anti-inflammatory and insulinsensitizing effects," Cell, vol. 142, no. 5, pp. 687-698, 2010.

[94] M. T. A. Nguyen, A. Chen, W. J. Lu et al., "Regulation of chemokine and chemokine receptor expression by PPAR $\gamma$ in adipocytes and macrophages," PLoS ONE, vol. 7, no. 4, Article ID e34976, 2012.

[95] J. G. Neels, L. Badeanlou, K. D. Hester, and F. Samad, "Keratinocyte-derived chemokine in obesity. Expression, regulation, and role in adipose macrophage infiltration and glucose homeostasis," Journal of Biological Chemistry, vol. 284, no. 31, pp. 20692-20698, 2009.

[96] C. Y. Han, A. Y. Kargi, M. Omer et al., "Differential effect of saturated and unsaturated free fatty acids on the generation of monocyte adhesion and chemotactic factors by adipocytes: dissociation of adipocyte hypertrophy from inflammation," Diabetes, vol. 59, no. 2, pp. 386-396, 2010.

[97] S. Fu, S. M. Watkins, and G. S. Hotamisligil, "The role of endoplasmic reticulum in hepatic lipid homeostasis and stress signaling," Cell Metabolism, vol. 15, no. 5, pp. 623-634, 2012.

[98] F. Engin and G. S. Hotamisligil, "Restoring endoplasmic reticulum function by chemical chaperones: an emerging therapeutic approach for metabolic diseases," Diabetes, Obesity and Metabolism, vol. 12, no. 2, pp. 108-115, 2010.

[99] M. T. A. Nguyen, A. Chen, W. J. Lu et al., "Regulation of chemokine and chemokine receptor expression by PPAR $\gamma$ in adipocytes and macrophages," PLoS ONE, vol. 7, no. 4, Article ID e34976, 2012.

[100] D. Patsouris, J. G. Neels, W. Q. Fan, P. P. Li, M. T. A. Nguyen, and J. M. Olefsky, "Glucocorticoids and thiazolidinediones interfere with adipocyte-mediated macrophage chemotaxis and recruitment," Journal of Biological Chemistry, vol. 284, no. 45, pp. 31223-31235, 2009.

[101] R. Stienstra, C. Duval, S. Keshtkar, J. Van Der Laak, S. Kersten, and M. Müller, "Peroxisome proliferator-activated receptor $\gamma$ activation promotes infiltration of alternatively activated macrophages into adipose tissue," Journal of Biological Chemistry, vol. 283, no. 33, pp. 22620-22627, 2008.

[102] G. Pascual, A. L. Sullivan, S. Ogawa et al., "Anti-inflammatory and antidiabetic roles of PPARy," Novartis Foundation Symposium, vol. 286, pp. 183-196, 2007.

[103] F. M. Gregoire, F. Zhang, H. J. Clarke et al., "MBX-102/ JNJ39659100, a novel peroxisome proliferator-activated receptor-ligand with weak transactivation activity retains antidiabetic properties in the absence of weight gain and edema," Molecular Endocrinology, vol. 23, no. 7, pp. 975-988, 2009.

[104] S. Ogawa, J. Lozach, C. Benner et al., "Molecular determinants of crosstalk between nuclear receptors and toll-like receptors," Cell, vol. 122, no. 5, pp. 707-721, 2005.

[105] S. Ghisletti, W. Huang, S. Ogawa et al., "Parallel SUMOylationdependent pathways mediate Gene- and signal-specific transrepression by LXRs and PPAR $\gamma$," Molecular Cell, vol. 25, no. 1, pp. 57-70, 2007.
[106] S. Ghisletti, W. Huang, K. Jepsen et al., "Cooperative NCoR/ SMRT interactions establish a eorepressor-based strategy for integration of inflammatory ana anti-inflammatory signaling pathways," Genes and Development, vol. 23, no. 6, pp. 681-693, 2009.

[107] G. Pascual, A. L. Fong, S. Ogawa et al., "A SUMOylationdependent pathway mediates transrepression of inflammatory response genes by PPAR- $\gamma$," Nature, vol. 437, no. 7059, pp. 759$763,2005$.

[108] J. M. Olefsky and C. K. Glass, "Macrophages, inflammation, and insulin resistance," Annual Review of Physiology, vol. 72, pp. 219246, 2010.

[109] A. L. Hevener, J. M. Olefsky, D. Reichart et al., "Macrophage $\operatorname{PPAR} \gamma$ is required for normal skeletal muscle and hepatic insulin sensitivity and full antidiabetic effects of thiazolidinediones," Journal of Clinical Investigation, vol. 117, no. 6, pp. 1658-1669, 2007.

[110] J. I. Odegaard, R. R. Ricardo-Gonzalez, M. H. Goforth et al., "Macrophage-specific PPAR $\gamma$ controls alternative activation and improves insulin resistance," Nature, vol. 447, no. 7148, pp. 1116-1120, 2007.

[111] C. N. Lumeng, J. L. Bodzin, and A. R. Saltiel, "Obesity induces a phenotypic switch in adipose tissue macrophage polarization," Journal of Clinical Investigation, vol. 117, no. 1, pp. 175-184, 2007.

[112] M. G. Hunter, L. Bawden, D. Brotherton et al., "BB-10010: an active variant of human macrophage inflammatory protein- $1 \alpha$ with improved pharmaceutical properties," Blood, vol. 86, no. 12, pp. 4400-4408, 1995.

[113] J. I. Odegaard and A. Chawla, "Alternative macrophage activation and metabolism," Annual Review of Pathology, vol. 6, pp. 275-297, 2011.

[114] A. Chawla, "Control of macrophage activation and function by PPARs," Circulation Research, vol. 106, no. 10, pp. 1559-1569, 2010.

[115] M. Feuerer, L. Herrero, D. Cipolletta et al., "Lean, but not obese, fat is enriched for a unique population of regulatory $\mathrm{T}$ cells that affect metabolic parameters," Nature Medicine, vol. 15, no. 8, pp. 930-939, 2009.

[116] D. Cipolletta, M. Feuerer, A. Li, J. Lee, S. E. Shoelson, and D. Mathis, "PPAR- $\gamma$ is a major driver of the accumulation and phenotype of adipose tissue T reg cells," Nature, vol. 486, no. 7404, pp. 549-553, 2012.

[117] M. Hamaguchi and S. Sakaguchi, "Regulatory T cells expressing PPAR- $\gamma$ control inflammation in obesity," Cell Metabolism, vol. 16, no. 1, pp. 4-6, 2012.

[118] M. Rakhshandehroo, B. Knoch, M. Müller, and S. Kersten, "Peroxisome proliferator-activated receptor alpha target genes," PPAR Research, vol. 2010, Article ID 612089, 20 pages, 2010.

[119] S. Mandard, M. Müller, and S. Kersten, "Peroxisome proliferator-activated receptor $\alpha$ target genes," Cellular and Molecular Life Sciences, vol. 61, no. 4, pp. 393-416, 2004.

[120] V. R. Narala, R. K. Adapala, M. V. Suresh, T. G. Brock, M. Peters-Golden, and R. C. Reddy, "Leukotriene B4 is a physiologically relevant endogenous peroxisome proliferator-activated receptor- $\alpha$ agonist," Journal of Biological Chemistry, vol. 285, no. 29, pp. 22067-22074, 2010.

[121] J. Lo Verme, J. Fu, G. Astarita et al., “The nuclear receptor peroxisome proliferator-activated receptor- $\alpha$ mediates the antiinflammatory actions of palmitoylethanolamide," Molecular Pharmacology, vol. 67, no. 1, pp. 15-19, 2005. 
[122] S. S. T. Lee, T. Pineau, J. Drago et al., "Targeted disruption of the $\alpha$ isoform of the peroxisome proliferator-activated receptor gene in mice results in abolishment of the pleiotropic effects of peroxisome proliferators," Molecular and Cellular Biology, vol. 15, no. 6, pp. 3012-3022, 1995.

[123] C. Duval, U. Thissen, S. Keshtkar et al., "Adipose tissue dysfunction signals progression of hepatic steatosis towards nonalcoholic steatohepatitis in C57Bl/6 mice," Diabetes, vol. 59, no. 12, pp. 3181-3191, 2010.

[124] M. Pini, D. H. Rhodes, and G. Fantuzzi, "Hematological and acute-phase responses to diet-induced obesity in IL-6 KO mice," Cytokine, vol. 56, no. 3, pp. 708-716, 2011.

[125] F. Lalloyer, K. Wouters, M. Baron et al., "Peroxisome proliferator-activated receptor- $\alpha$ gene level differently affects lipid metabolism and inflammation in apolipoprotein E2 knock-in mice," Arteriosclerosis, Thrombosis, and Vascular Biology, vol. 31, no. 7, pp. 1573-1579, 2011.

[126] R. Shiri-Sverdlov, K. Wouters, P. J. V. Gorp et al., "Early dietinduced non-alcoholic steatohepatitis in APOE2 knock-in mice and its prevention by fibrates," Journal of Hepatology, vol. 44, no. 4, pp. 732-741, 2006.

[127] R. Stienstra, F. Saudale, C. Duval et al., "Kupffer cells promote hepatic steatosis via interleukin- $1 \beta$-dependent suppression of peroxisome proliferator-activated receptor $\alpha$ activity," Hepatology, vol. 51, no. 2, pp. 511-522, 2010.

[128] P. Delerive, P. Gervois, J. C. Fruchart, and B. Staels, "Induction of $\mathrm{I} \kappa \mathrm{B} \alpha$ expression as a mechanism contributing to the antiinflammatory activities of peroxisome proliferator-activated receptor- $\alpha$ activators," Journal of Biological Chemistry, vol. 275, no. 47, pp. 36703-36707, 2000.

[129] P. Gervois, N. Vu-Dac, R. Kleemann et al., "Negative regulation of human fibrinogen gene expression by peroxisome proliferator-activated receptor alpha agonists via inhibition of CCAAT box/enhancer-binding protein beta," Journal of Biological Chemistry, vol. 276, no. 36, pp. 33471-33477, 2001.

[130] N. Bougarne, R. Paumelle, S. Caron et al., "PPAR $\alpha$ blocks glucocorticoid receptor $\alpha$-mediated transactivation but cooperates with the activated glucocorticoid receptor $\alpha$ for transrepression on NF- $\kappa \mathrm{B}$," Proceedings of the National Academy of Sciences of the United States of America, vol. 106, no. 18, pp. 7397-7402, 2009.

[131] R. Stienstra, S. Mandard, N. S. Tan et al., "The Interleukin-1 receptor antagonist is a direct target gene of PPAR $\alpha$ in liver," Journal of Hepatology, vol. 46, no. 5, pp. 869-877, 2007.

[132] M. François, P. Richette, L. Tsagris et al., "Activation of the peroxisome proliferator-activated receptor $\alpha$ pathway potentiates interleukin-1 receptor antagonist production in cytokinetreated chondrocytes," Arthritis and Rheumatism, vol. 54, no. 4, pp. 1233-1245, 2006.

[133] J. S. Moffit, P. H. Koza-Taylor, R. D. Holland et al., "Differential gene expression in mouse liver associated with the hepatoprotective effect of clofibrate," Toxicology and Applied Pharmacology, vol. 222, no. 2, pp. 169-179, 2007.

[134] A. Rogue, C. Lambert, R. Jossé, S. Antherieu, C. Spire, and A. Guillouzo, "Comparative gene expression profiles induced by PPAR $\gamma$ and PPAR $\alpha / \gamma$ agonists in human hepatocytes," PLoS ONE, vol. 6, no. 4, Article ID e18816, 2011.

[135] J. S. Wong and S. S. Gill, "Gene expression changes induced in mouse liver by di(2-ethylhexyl) phthalate," Toxicology and Applied Pharmacology, vol. 185, no. 3, pp. 180-196, 2002.

[136] M. Rakhshandehroo, R. Stienstra, N. J. de Wit et al., "Plasma mannose-binding lectin is stimulated by PPAR $\alpha$ in humans,"
American Journal of Physiology, vol. 302, no. 5, pp. E595-E602, 2012.

[137] M. Pang, S. M. de la Monte, L. Longato et al., "PPAR $\delta$ agonist attenuates alcohol-induced hepatic insulin resistance and improves liver injury and repair," Journal of Hepatology, vol. 50, no. 6, pp. 1192-1201, 2009.

[138] K. Hellemans, L. Michalik, A. Dittie et al., "Peroxisome proliferator-activated receptor- $\beta$ signaling contributes to enhanced proliferation of hepatic stellate cells," Gastroenterology, vol. 124, no. 1, pp. 184-201, 2003.

[139] L. M. Sanderson, M. V. Boekschoten, B. Desvergne, M. Müller, and S. Kersten, "Transcriptional profiling reveals divergent roles of PPAR $\alpha$ and PPAR $\beta / \delta$ in regulation of gene expression in mouse liver," Physiological Genomics, vol. 41, no. 1, pp. 42-52, 2010.

[140] W. Shan, C. J. Nicol, S. Ito et al., "Peroxisome proliferator-activated receptor- $\beta / \delta$ protects against chemically induced liver toxicity in mice," Hepatology, vol. 47, no. 1, pp. 225-235, 2008.

[141] S. Liu, B. Hatano, M. Zhao et al., "Role of peroxisome proliferator-activated receptor $\delta / \beta$ in hepatic metabolic regulation," Journal of Biological Chemistry, vol. 286, no. 2, pp. 1237-1247, 2011.

[142] M. Y. Lee, R. Choi, H. M. Kim et al., "Peroxisome proliferatoractivated receptor $\delta$ agonist attenuates hepatic steatosis by anti-inflammatory mechanism," Experimental and Molecular Medicine, vol. 44, no. 10, pp. 578-585, 2012.

[143] A. A. Sanchez-Siles, N. Ishimura, M. A. K. Rumi et al., "Administration of $\operatorname{PPAR} \beta / \delta$ agonist reduces copper-induced liver damage in mice: possible implications in clinical practice," Journal of Clinical Biochemistry and Nutrition, vol. 49, no. 1, pp. 4249, 2011.

[144] K. Iwaisako, M. Haimerl, Y.-H. Paik et al., "Protection from liver fibrosis by a peroxisome proliferator-activated receptor $\delta$ agonist," Proceedings of the National Academy of Sciences of the United States of America, vol. 109, no. 21, pp. E1369-E1376, 2012.

[145] B. Gross, N. Hennuyer, E. Bouchaert et al., "Generation and characterization of a humanized PPAR $\delta$ mouse model," British Journal of Pharmacology, vol. 164, no. 1, pp. 192-208, 2011.

[146] E. Morán-Salvador, M. López-Parra, V. García-Alonso et al., "Role for PPAR $\gamma$ in obesity-induced hepatic steatosis as determined by hepatocyte- and macrophage-specific conditional knockouts," FASEB Journal, vol. 25, no. 8, pp. 2538-2550, 2011.

[147] V. Gazit, J. Huang, A. Weymann, and D. A. Rudnick, "Analysis of the role of hepatic PPAR $\gamma$ expression during mouse liver regeneration," Hepatology, vol. 56, no. 4, pp. 1489-1498, 2012.

[148] Z. Chen, P. A. Vigueira, N. Qi et al., "Insulin resistance and metabolic derangements in obese mice are ameliorated by a novel peroxisome proliferator-activated receptor $\gamma$-sparing thiazolidinedione," Journal of Biological Chemistry, vol. 287, no. 28, pp. 23537-23548, 2012.

[149] Z. Han, T. Zhu, X. Liu et al., "15-deoxy- $\Delta^{12,14}$-prostaglandin $J_{2}$ reduces recruitment of bone marrow-derived monocyte/macrophages in chronic liver injury in mice," Hepatology, vol. 56, no. 1, pp. 350-360, 2012.

[150] B. Lu, A. H. Moser, J. K. Shigenaga, K. R. Feingold, and C. Grunfeld, "Type II nuclear hormone receptors, coactivator, and target gene repression in adipose tissue in the acute-phase response," Journal of Lipid Research, vol. 47, no. 10, pp. 21792190, 2006.

[151] A. P. Beigneux, A. H. Moser, J. K. Shigenaga, C. Grunfeld, and K. R. Feingold, "The acute phase response is associated 
with retinoid X receptor repression in rodent liver," Journal of Biological Chemistry, vol. 275, no. 21, pp. 16390-16399, 2000.

[152] M. R. Hill, M. D. Young, C. M. Mccurdy, and J. M. Gimble, "Decreased expression of murine PPAR $\gamma$ in adipose tissue during endotoxemia," Endocrinology, vol. 138, no. 7, pp. 30733076, 1997.

[153] M. S. Kim, J. Shigenaga, A. Moser, K. Feingold, and C. Grunfeld, "Repression of farnesoid X receptor during the acute phase response," Journal of Biological Chemistry, vol. 278, no. 11, pp. 8988-8995, 2003.

[154] K. Feingold, M. S. Kim, J. Shigenaga, A. Moser, and C. Grunfeld, "Altered expression of nuclear hormone receptors and coactivators in mouse heart during the acute-phase response," American Journal of Physiology, vol. 286, no. 2, pp. E201-E207, 2004.

[155] M. S. Kim, T. R. Sweeney, J. K. Shigenaga et al., "Tumor necrosis factor and interleukin 1 decrease $\operatorname{RXR} \alpha, \operatorname{PPAR} \alpha, \operatorname{PPAR} \gamma, \operatorname{LXR} \alpha$, and the coactivators SRC-1, PGC- $1 \alpha$, and PGC- $1 \beta$ in liver cells," Metabolism, vol. 56, no. 2, pp. 267-279, 2007.

[156] Z. Haskova, B. Hoang, G. Luo et al., "Modulation of LPSinduced pulmonary neutrophil infiltration and cytokine production by the selective PPAR $\beta / \delta$ ligand GW0742," Inflammation Research, vol. 57, no. 7, pp. 314-321, 2008.

[157] M. R. Hill, S. Clarke, K. Rodgers et al., "Effect of peroxisome proliferator-activated receptor alpha activators on tumor necrosis factor expression in mice during endotoxemia," Infection and Immunity, vol. 67, no. 7, pp. 3488-3493, 1999.

[158] K. R. Feingold, Y. Wang, A. Moser, J. K. Shigenaga, and C. Grunfeld, "LPS decreases fatty acid oxidation and nuclear hormone receptors in the kidney," Journal of Lipid Research, vol. 49, no. 10, pp. 2179-2187, 2008.

[159] T. B. Barclay, J. M. Peters, M. B. Sewer, L. Ferrari, F. J. Gonzalez, and E. T. Morgan, "Modulation of cytochrome P450 gene expression in endotoxemic mice is tissue specific and peroxisome proliferator-activated receptor- $\alpha$ dependent," Journal of Pharmacology and Experimental Therapeutics, vol. 290, no. 3, pp. 1250-1257, 1999.

[160] R. Stienstra, F. Saudale, C. Duval et al., "Kupffer cells promote hepatic steatosis via interleukin- $1 \beta$-dependent suppression of peroxisome proliferator-activated receptor $\alpha$ activity," Hepatology, vol. 51, no. 2, pp. 511-522, 2010.

[161] C. K. Mulvey, J. F. Ferguson, and J. Tabita-Martinez, "Peroxisome proliferator-activated receptor-alpha agonism with fenofibrate does not suppress inflammatory responses to evoked endotoxemia," Journal of the American Heart Association, vol. 1, no. 4, Article ID e002923, 2012.

[162] C. N. A. Palmer, M. H. Hsu, K. J. Griffin, J. L. Raucy, and E. F. Johnson, "Peroxisome proliferator activated receptor- $\alpha$ expression in human liver," Molecular Pharmacology, vol. 53, no. 1, pp. 14-22, 1998.

[163] P. Gervois, R. Kleemann, A. Pilon et al., "Global suppression of IL-6-induced acute phase response gene expression after chronic in vivo treatment with the peroxisome proliferatoractivated receptor-alpha activator fenofibrate," Journal of Biological Chemistry, vol. 279, no. 16, pp. 16154-16160, 2004.

[164] I. J. Jonkers, M. F. Mohrschladt, R. G. Westendorp, A. Van der Laarse, and A. H. Smelt, "Severe hypertriglyceridemia with insulin resistance is associated with systemic inflammation: reversal with bezafibrate therapy in a randomized controlled trial," American Journal of Medicine, vol. 112, no. 4, pp. 275-280, 2002.

[165] E. Jozefowicz, H. Brisson, S. Rozenberg et al., "Activation of peroxisome proliferator-activated receptor- $\alpha$ by fenofibrate prevents myocardial dysfunction during endotoxemia in rats," Critical Care Medicine, vol. 35, no. 3, pp. 856-863, 2007.

[166] R. M. Mansouri, E. Baugé, B. Staels, and P. Gervois, "Systemic and distal repercussions of liver-specific peroxisome proliferator-activated receptor- $\alpha$ control of the acute-phase response," Endocrinology, vol. 149, no. 6, pp. 3215-3223, 2008.

[167] A. Kapoor, Y. Shintani, M. Collino et al., "Protective role of peroxisome proliferator-activated receptor- $\beta / \delta$ in septic shock," American Journal of Respiratory and Critical Care Medicine, vol. 182, no. 12, pp. 1506-1515, 2010.

[168] D. Liu, B. X. Zeng, S. H. Zhang et al., "Rosiglitazone, a peroxisome proliferator-activated receptor- $\gamma$ agonist, reduces acute lung injury in endotoxemic rats," Critical Care Medicine, vol. 33, no. 10, pp. 2309-2316, 2005.

[169] D. Liu, B. X. Zeng, S. H. Zhang, and S. L. Yao, "Rosiglitazone, an agonist of peroxisome proliferator-activated receptor $\gamma$, reduces pulmonary inflammatory response in a rat model of endotoxemia," Inflammation Research, vol. 54, no. 11, pp. 464470, 2005.

[170] M. Collin, N. S. A. Patel, L. Dugo, and C. Thiemermann, "Role of peroxisome proliferator-activated receptor- $\gamma$ in the protection afforded by 15 -deoxy $\Delta 12,14$ prostaglandin $\mathrm{J} 2$ against the multiple organ failure caused by endotoxin," Critical Care Medicine, vol. 32, no. 3, pp. 826-831, 2004.

[171] J. S. Hwang, E. S. Kang, S. A. Ham et al., "Activation of peroxisome proliferator-activated receptor $\gamma$ by rosiglitazone inhibits lipopolysaccharide-induced release of high mobility group box 1," Mediators of Inflammation, vol. 2012, Article ID 352807, 9 pages, 2012.

[172] R. Thieringer, J. E. Fenyk-Melody, C. B. Le Grand et al., "Activation of peroxisome proliferator-activated receptor $\gamma$ does not inhibit IL-6 or TNF- $\alpha$ responses of macrophages to lipopolysaccharide in vitro or in vivo," Journal of Immunology, vol. 164, no. 2, pp. 1046-1054, 2000.

[173] W. Fan, Y. Liu, Z. Wu et al., "Effects of rosiglitazone, an agonist of the peroxisome proliferator-activated receptor $\gamma$, on intestinal damage induced by Escherichia coli lipopolysaccharide in weaned pigs," American Journal of Veterinary Research, vol. 71, no. 11, pp. 1331-1338, 2010.

[174] Y. Liu, J. Shi, J. Lu et al., "Activation of peroxisome proliferatoractivated receptor- $\gamma$ potentiates pro-inflammatory cytokine production, and adrenal and somatotropic changes of weaned pigs after Escherichia coli lipopolysaccharide challenge," Innate Immunity, vol. 15, no. 3, pp. 169-178, 2009.

[175] M. Bünger, H. M. Van Den Bosch, J. Van Der Meijde, S. Kersten, G. J. E. J. Hooiveld, and M. Müller, "Genome-wide analysis of PPAR $\alpha$ activation in murine small intestine," Physiological Genomics, vol. 30, no. 2, pp. 192-204, 2007.

[176] A. Mansén, H. Guardiola-Diaz, J. Rafter, C. Branting, and J. Å. Gustafsson, "Expression of the peroxisome proliferator-activated receptor (PPAR) in the mouse colonic mucosa," Biochemical and Biophysical Research Communications, vol. 222, no. 3, pp. 844-851, 1996.

[177] Y. T. Azuma, K. Nishiyama, Y. Matsuo et al., "PPAR $\alpha$ contributes to colonic protection in mice with DSS-induced colitis," International Immunopharmacology, vol. 10, no. 10, pp. 1261-1267, 2010.

[178] L. Riccardi, E. Mazzon, S. Bruscoli et al., "Peroxisome proliferator-activated receptor- $\alpha$ modulates the anti-inflammatory effect of glucocorticoids in a model of inflammatory bowel disease in mice," Shock, vol. 31, no. 3, pp. 308-316, 2009.

[179] S. Cuzzocrea, R. Di Paola, E. Mazzon et al., "Role of endogenous and exogenous ligands for the peroxisome proliferators 
activated receptors alpha (PPAR- $\alpha$ ) in the development of inflammatory bowel disease in mice," Laboratory Investigation, vol. 84, no. 12, pp. 1643-1654, 2004.

[180] H. E. Hollingshead, K. Morimura, M. Adachi et al., "PPAR $\beta / \delta$ protects against experimental colitis through a ligandindependent mechanism," Digestive Diseases and Sciences, vol. 52, no. 11, pp. 2912-2919, 2007.

[181] W. Su, C. R. Bush, B. M. Necela et al., "Differential expression, distribution, and function of PPAR- $\gamma$ in the proximal and distal colon," Physiological Genomics, vol. 30, no. 3, pp. 342-353, 2007.

[182] A. M. Lefebvre, I. Chen, P. Desreumaux et al., "Activation of the peroxisome proliferator-activated receptor $\gamma$ promotes the development of colon tumors in C57BL/6J-APC(Min)/+ mice," Nature Medicine, vol. 4, no. 9, pp. 1053-1057, 1998.

[183] E. Saez, P. Tontonoz, M. C. Nelson et al., "Activators of the nuclear receptor PPAR $\gamma$ enhance colon polyp formation," Nature Medicine, vol. 4, no. 9, pp. 1058-1061, 1998.

[184] G. D. Girnun, W. M. Smith, S. Drori et al., "APC-dependent suppression of colon carcinogenesis by PPAR $\gamma$," Proceedings of the National Academy of Sciences of the United States of America, vol. 99, no. 21, pp. 13771-13776, 2002.

[185] L. Dubuquoy, E. Å Jansson, S. Deeb et al., "Impaired expression of peroxisome proliferator-activated receptor $\gamma$ in ulcerative colitis," Gastroenterology, vol. 124, no. 5, pp. 1265-1276, 2003.

[186] N. P. Evans, S. A. Misyak, E. M. Schmelz, A. J. Guri, R. Hontecillas, and J. Bassaganya-Riera, "Conjugated linoleic acid ameliorates inflammation-induced colorectal cancer in mice through activation of PPAR $\gamma$," Journal of Nutrition, vol. 140, no. 3, pp. 515-521, 2010.

[187] M. Adachi, R. Kurotani, K. Morimura et al., "Peroxisome proliferator activated receptor $\gamma$ in colonic epithelial cells protects against experimental inflammatory bowel disease," Gut, vol. 55, no. 8, pp. 1104-1113, 2006.

[188] D. Kelly, J. I. Campbell, T. P. King et al., "Commensal anaerobic gut bacteria attenuate inflammation by regulating nuclearcytoplasmic shutting of PPAR- $\gamma$ and ReIA," Nature Immunology, vol. 5, no. 1, pp. 104-112, 2004.

[189] J. Mwinyi, C. Grete-Wenger, J. J. Eloranta, and G. A. KullakUblick, "The impact of PPAR $\gamma$ genetic variants on IBD susceptibility and IBD disease course," PPAR Research, vol. 2012, Article ID 349469, 13 pages, 2012.

[190] A. J. Guri, S. K. Mohapatra, W. T. Horne, R. Hontecillas, and J. Bassaganya-Riera, "The Role of T cell PPAR $\gamma$ in mice with experimental inflammatory bowel disease," BMC Gastroenterology, vol. 10, article 60, 2010.

[191] R. Hontecillas, W. T. Horne, M. Climent et al., "Immunoregulatory mechanisms of macrophage PPAR- $\gamma$ in mice with experimental inflammatory bowel disease," Mucosal Immunology, vol. 4, no. 3, pp. 304-313, 2011.

[192] R. Hontecillas and J. Bassaganya-Riera, "Peroxisome proliferator-activated receptor $\gamma$ is required for regulatory CD4+ T cell-mediated protection against colitis," Journal of Immunology, vol. 178, no. 5, pp. 2940-2949, 2007.

[193] S. Moreno, S. Farioli-vecchioli, and M. P. Cerù, "Immunolocalization of peroxisome proliferator-activated receptors and retinoid X receptors in the adult rat CNS," Neuroscience, vol. 123, no. 1, pp. 131-145, 2004.

[194] O. Braissant and W. Wahli, "Differential expression of peroxisome proliferator-activated receptor- $\alpha,-\beta$, and $-\gamma$ during rat embryonic development," Endocrinology, vol. 139, no. 6, pp. 2748-2754, 1998.
[195] P. Krémarik-Bouillaud, H. Schohn, and M. Dauça, "Regional distribution of PPAR $\beta$ in the cerebellum of the rat," Journal of Chemical Neuroanatomy, vol. 19, no. 4, pp. 225-232, 2000.

[196] A. Benani, P. Krémarik-Bouillaud, A. Bianchi, P. Netter, A. Minn, and M. Dauça, "Evidence for the presence of both peroxisome proliferator-activated receptors alpha and beta in the rat spinal cord," Journal of Chemical Neuroanatomy, vol. 25, no. 1, pp. 29-38, 2003.

[197] A. Benani, T. Heurtaux, P. Netter, and A. Minn, "Activation of peroxisome proliferator-activated receptor alpha in rat spinal cord after peripheral noxious stimulation," Neuroscience Letters, vol. 369, no. 1, pp. 59-63, 2004.

[198] G. D’Agostino, G. La Rana, R. Russo et al., "Acute intracerebroventricular administration of palmitoylethanolamide, an endogenous peroxisome proliferator-activated receptor- $\alpha$ agonist, modulates carrageenan-induced paw edema in mice," Journal of Pharmacology and Experimental Therapeutics, vol. 322, no. 3, pp. 1137-1143, 2007.

[199] A. Defaux, M. G. Zurich, O. Braissant, P. Honegger, and F. Monnet-Tschudi, "Effects of the PPAR- $\beta$ agonist GW501516 in an in vitro model of brain inflammation and antibody-induced demyelination," Journal of Neuroinflammation, vol. 6, article 15, 2009.

[200] P. E. Polak, S. Kalinin, C. Dello Russo et al., "Protective effects of a peroxisome proliferator-activated receptor- $\beta / \delta$ agonist in experimental autoimmune encephalomyelitis," Journal of Neuroimmunology, vol. 168, no. 1-2, pp. 65-75, 2005.

[201] M. Jana and K. Pahan, "Gemfibrozil, a lipid lowering drug, inhibits the activation of primary human microglia via peroxisome proliferator-activated receptor $\beta$," Neurochemical Research, vol. 37, no. 5, pp. 1718-1729, 2012.

[202] H. E. Kocalis, M. K. Turney, R. L. Printz et al., "Neuron-specific deletion of peroxisome proliferator-activated receptor delta $(\operatorname{PPAR} \delta)$ in mice leads to increased susceptibility to dietinduced obesity," PLoS ONE, vol. 7, no. 8, Article ID e42981, 2012.

[203] T. Breidert, J. Callebert, M. T. Heneka, G. Landreth, J. M. Launay, and E. C. Hirsch, "Protective action of the peroxisome proliferator-activated receptor- $\gamma$ agonist pioglitazone in a mouse model of Parkinson's disease," Journal of Neurochemistry, vol. 82, no. 3, pp. 615-624, 2002.

[204] T. Dehmer, M. T. Heneka, M. Sastre, J. Dichgans, and J. B. Schulz, "Protection by pioglitazone in the MPTP model of Parkinson's disease correlates with $\mathrm{I} \kappa \mathrm{B} \alpha$ induction and block of $\mathrm{NF} \kappa \mathrm{B}$ and iNOS activation," Journal of Neurochemistry, vol. 88, no. 2, pp. 494-501, 2004.

[205] P. Lockyer, J. C. Schisler, C. Patterson, and M. S. Willis, "Minireview: won't get fooled again: the nonmetabolic roles of peroxisome proliferator-activated receptors (PPARs) in the heart," Molecular Endocrinology, vol. 24, no. 6, pp. 1111-1119, 2010.

[206] T. Ogata, T. Miyauchi, S. Sakai, M. Takanashi, Y. IrukayamaTomobe, and I. Yamaguchi, "Myocardial fibrosis and diastolic dysfunction in deoxycorticosterone acetate-salt hypertensive rats is ameliorated by the peroxisome proliferator-activated receptor-alpha activator fenofibrate, partly by suppressing inflammatory responses associated with the nuclear factorkappa-B pathway," Journal of the American College of Cardiology, vol. 43, no. 8, pp. 1481-1488, 2004.

[207] A. Georgiadi, M. V. Boekschoten, M. Müller, and S. Kersten, "Detailed transcriptomics analysis of the effect of dietary fatty acids on gene expression in the heart," Physiological Genomics, vol. 44, no. 6, pp. 352-361, 2012. 
[208] P. J. H. Smeets, H. M. De Vogel-van Den Bosch, P. H. M. Willemsen et al., "Transcriptomic analysis of PPAR $\alpha$-dependent alterations during cardiac hypertrophy," Physiological Genomics, vol. 36, no. 1, pp. 15-23, 2008.

[209] P. J. H. Smeets, B. E. J. Teunissen, A. Planavila et al., "Inflammatory pathways are activated during cardiomyocyte hypertrophy and attenuated by peroxisome proliferator-activated receptors PPAR $\alpha$ and PPAR $\delta$," Journal of Biological Chemistry, vol. 283, no. 43, pp. 29109-29118, 2008.

[210] G. Ding, L. Cheng, Q. Qin, S. Frontin, and Q. Yang, "PPAR $\delta$ modulates lipopolysaccharide-induced TNF $\alpha$ inflammation signaling in cultured cardiomyocytes," Journal of Molecular and Cellular Cardiology, vol. 40, no. 6, pp. 821-828, 2006.

[211] D. Álvarez-Guardia, X. Palomer, T. Coll et al., "PPAR $\beta / \delta$ activation blocks lipid-induced inflammatory pathways in mouse heart and human cardiac cells," Biochimica et Biophysica Acta, vol. 1811, no. 2, pp. 59-67, 2011.

[212] F. Penas, G. A. Mirkin, E. Hovsepian et al., "PPAR $\gamma$ ligand treatment inhibits cardiac inflammatory mediators induced by infection with different lethality strains of Trypanosoma cruzi," Biochimica et Biophysica Acta, vol. 1832, no. 1, pp. 239-248, 2013.

[213] E. Hovsepian, G. A. Mirkin, F. Penas, A. Manzano, R. Bartrons, and N. B. Goren, "Modulation of inflammatory response and parasitism by 15 -Deoxy- $\Delta 12,14$ prostaglandin 22 in Trypanosoma cruzi-infected cardiomyocytes," International Journal for Parasitology, vol. 41, no. 5, pp. 553-562, 2011.

[214] G. Reiterer, M. Toborek, and B. Hennig, "Peroxisome proliferator activated receptors $\alpha$ and $\gamma$ require zinc for their anti-inflammatory properties in porcine vascular endothelial cells," Journal of Nutrition, vol. 134, no. 7, pp. 1711-1715, 2004.

[215] N. Wang, L. Verna, N. G. Chen et al., "Constitutive activation of peroxisome proliferator-activated receptor- $\gamma$ suppresses proinflammatory adhesion molecules in human vascular endothelial cells," Journal of Biological Chemistry, vol. 277, no. 37, pp. 34176-34181, 2002.

[216] Y. Rival, N. Benéteau, T. Taillandier et al., "PPAR $\alpha$ and PPAR $\delta$ activators inhibit cytokine-induced nuclear translocation of NF- $\kappa$ B and expression of VCAM-1 in EAhy926 endothelial cells," European Journal of Pharmacology, vol. 435, no. 2-3, pp. 143-151, 2002.

[217] J. Berger, M. D. Leibowitz, T. W. Doebber et al., "Novel peroxisome proliferator-activated receptor (PPAR) $\gamma$ and PPAR $\delta$ ligands produce distinct biological effects," Journal of Biological Chemistry, vol. 274, no. 10, pp. 6718-6725, 1999.

[218] Y. J. Liang, Y. C. Liu, C. Y. Chen et al., "Comparison of PPAR $\delta$ and PPAR $\gamma$ in inhibiting the pro-inflammatory effects of Creactive protein in endothelial cells," International Journal of Cardiology, vol. 143, no. 3, pp. 361-367, 2010.

[219] Y. Fan, Y. Wang, Z. Tang et al., "Suppression of pro-inflammatory adhesion molecules by PPAR- $\delta$ in human vascular endothelial cells," Arteriosclerosis, Thrombosis, and Vascular Biology, vol. 28, no. 2, pp. 315-321, 2008.

[220] C. H. Lee, A. Chawla, N. Urbiztondo, D. Liao, W. A. Boisvert, and R. M. Evans, "Transcriptional repression of atherogenic inflammation: modulation by PPAR $\delta$," Science, vol. 302, no. 5644, pp. 453-457, 2003.

[221] Y. S. Maeng, J. K. Min, J. H. Kim et al., "ERK is an anti-inflammatory signal that suppresses expression of NF- $\kappa \mathrm{B}$-dependent inflammatory genes by inhibiting IKK activity in endothelial cells," Cellular Signalling, vol. 18, no. 7, pp. 994-1005, 2006.
[222] C. H. Woo, M. P. Massett, T. Shishido et al., "ERK5 activation inhibits inflammatory responses via peroxisome proliferatoractivated receptor $\delta$ (PPAR $\delta$ ) stimulation," Journal of Biological Chemistry, vol. 281, no. 43, pp. 32164-32174, 2006.

[223] P. Delerive, F. Martin-Nizard, G. Chinetti et al., "Peroxisome proliferator-activated receptor activators inhibit thrombininduced endothelin-1 production in human vascular endothelial cells by inhibiting the activator protein-1 signaling pathway," Circulation Research, vol. 85, no. 5, pp. 394-402, 1999.

[224] N. Marx, T. Bourcier, G. K. Sukhova, P. Libby, and J. Plutzky, "PPAR $\gamma$ activation in human endothelial cells increases plasminogen activator inhibitor type- 1 expression: $\operatorname{PPAR} \gamma$ as a potential mediator in vascular disease," Arteriosclerosis, Thrombosis, and Vascular Biology, vol. 19, no. 3, pp. 546-551, 1999.

[225] N. Marx, F. Mach, A. Sauty et al., "Peroxisome proliferatoractivated receptor- $\gamma$ activators inhibit IFN- $\gamma$-induced expression of the T cell-active CXC chemokines IP-10, Mig, and I-TAC in human endothelial cells," Journal of Immunology, vol. 164, no. 12, pp. 6503-6508, 2000.

[226] V. Pasceri, H. D. Wu, J. T. Willerson, and E. T. H. Yeh, "Modulation of vascular inflammation in vitro and in vivo by peroxisome proliferator-activated receptor- $\gamma$ activators," Circulation, vol. 101, no. 3, pp. 235-238, 2000.

[227] A. Qu, Y. M. Shah, S. K. Manna, and F. J. Gonzalez, "Disruption of endothelial peroxisome proliferator-activated receptor $\gamma$ accelerates diet-induced atherogenesis in LDL receptor-null mice," Arteriosclerosis, Thrombosis, and Vascular Biology, vol. 32, no. 1, pp. 65-73, 2012.

[228] A. T. Reddy, S. P. Lakshmi, J. M. Kleinhenz, R. L. Sutliff, C. M. Hart, and R. C. Reddy, "Endothelial cell peroxisome proliferator-activated receptor $\gamma$ reduces endotoxemic pulmonary inflammation and injury," Journal of Immunology, vol. 189, no. 11, pp. 5411-5420, 2012.

[229] B. Desvergne and W. Wahli, "Peroxisome proliferator-activated receptors: nuclear control of metabolism," Endocrine Reviews, vol. 20, no. 5, pp. 649-688, 1999.

[230] R. J. Harmon, "Physiology of mastitis and factors affecting somatic cell counts," Journal of Dairy Science, vol. 77, no. 7, pp. 21032112, 1994.

[231] S. Uthaisangsook, N. K. Day, S. L. Bahna, R. A. Good, and S. Haraguchi, "Innate immunity and its role against infections," Annals of Allergy, Asthma and Immunology, vol. 88, no. 3, pp. 253-264, 2002.

[232] B. Buitenhuis, C. M. Røntved, S. M. Edwards, K. L. Ingvartsen, and P. Sørensen, "In depth analysis of genes and pathways of the mammary gland involved in the pathogenesis of bovine Escherichia coli-mastitis," BMC Genomics, vol. 12, article 130, 2011.

[233] R. S. Schweiker, "ACLI presidential address. American Council of Life Insurance," Transactions of the Association of Life Insurance Medical Directors of America, vol. 74, pp. 14-22, 1991.

[234] D. Yang, H. Yang, W. Li et al., "Generation of PPAR $\gamma$ monoallelic knockout pigs via zinc-finger nucleases and nuclear transfer cloning," Cell Research, vol. 21, no. 6, pp. 979-982, 2011.

[235] K. M. Moyes, J. K. Drackley, D. E. Morin et al., "Gene network and pathway analysis of bovine mammary tissue challenged with Streptococcus uberis reveals induction of cell proliferation and inhibition of PPAR signaling as potential mechanism for the negative relationships between immune response and lipid metabolism," BMC Genomics, vol. 10, article 542, 2009. 
[236] P. Gervois and R. M. Mansouri, "PPAR $\alpha$ as a therapeutic target in inflammation-associated diseases," Expert Opinion on Therapeutic Targets, vol. 16, no. 11, pp. 1113-1125, 2012.

[237] G. Schlegel, J. Keller, F. Hirche et al., "Expression of genes involved in hepatic carnitine synthesis and uptake in dairy cows in the transition period and at different stages of lactation," $B M C$ Veterinary Research, vol. 8, article 28, 2012.

[238] C. Ribet, E. Montastier, C. Valle et al., "Peroxisome proliferatoractivated receptor- $\alpha$ control of lipid and glucose metabolism in human white adipocytes," Endocrinology, vol. 151, no. 1, pp. 123133, 2010.

[239] C. Huin, L. Corriveau, A. Bianchi et al., "Differential expression of peroxisome proliferator-activated receptors (PPARs) in the developing human fetal digestive tract," Journal of Histochemistry and Cytochemistry, vol. 48, no. 5, pp. 603-611, 2000.

[240] D. Feng, Y. Zhang, and G. Chen, "Cortical expression of peroxisome proliferator-activated receptor- $\alpha$ after human brain contusion," Journal of International Medical Research, vol. 36, no. 4, pp. 783-791, 2008.

[241] M. A. Jakobsen, R. K. Petersen, K. Kristiansen, M. Lange, and S. T. Lillevang, "Peroxisome proliferator-activated receptor $\alpha$, $\delta, \gamma 1$ and $\gamma 2$ expressions are present in human monocytederived dendritic cells and modulate dendritic cell maturation by addition of subtype-specific ligands," Scandinavian Journal of Immunology, vol. 63, no. 5, pp. 330-337, 2006.

[242] M. Bouwens, L. A. Afman, and M. Müller, "Activation of peroxisome proliferator-activated receptor alpha in human peripheral blood mononuclear cells reveals an individual gene expression profile response," BMC Genomics, vol. 9, article 262, 2008.

[243] S. T. Ding, A. P. Schinckel, T. E. Weber, and H. J. Mersmann, "Expression of porcine transcription factors and genes related to fatty acid metabolism in different tissues and genetic populations," Journal of Animal Science, vol. 78, no. 8, pp. 2127-2134, 2000.

[244] G. D. Barish, M. Downes, W. A. Alaynick et al., "A nuclear receptor atlas: macrophage activation," Molecular Endocrinology, vol. 19, no. 10, pp. 2466-2477, 2005.

[245] D. Patsouris, S. Mandard, P. J. Voshol et al., "PPAR $\alpha$ governs glycerol metabolism," Journal of Clinical Investigation, vol. 114, no. 1, pp. 94-103, 2004.

[246] T. Hashimoto, W. S. Cook, C. Qi, A. V. Yeldandi, J. K. Reddy, and M. S. Rao, "Defect in peroxisome proliferator-activated receptor $\alpha$-inducible fatty acid oxidation determines the severity of hepatic steatosis in response to fasting," Journal of Biological Chemistry, vol. 275, no. 37, pp. 28918-28928, 2000.

[247] S. K. Mohapatra, L. E. Cole, C. Evans et al., "Modulation of hepatic PPAR expression during Ft LVS LPS-induced protection from Francisella tularensis LVS infection," BMC Infectious Diseases, vol. 10, article 10, 2010.

[248] M. Fu, T. Sun, A. L. Bookout et al., "A nuclear receptor atlas: 3T3-L1 adipogenesis," Molecular Endocrinology, vol. 19, no. 10, pp. 2437-2450, 2005.

[249] H. Vosper, L. Patel, T. L. Graham et al., "The peroxisome proliferator-activated receptor $\delta$ promotes lipid accumulation in human macrophages," Journal of Biological Chemistry, vol. 276, no. 47, pp. 44258-44265, 2001.

[250] E. Lord, B. D. Murphy, J. A. Desmarais, S. Ledoux, D. Beaudry, and M. F. Palin, "Modulation of peroxisome proliferator-activated receptor $\delta$ and $\gamma$ transcripts in swine endometrial tissue during early gestation," Reproduction, vol. 131, no. 5, pp. 929942, 2006.
[251] Y. Guan, Y. Zhang, L. Davis, and M. D. Breyer, "Expression of peroxisome proliferator-activated receptors in urinary tract of rabbits and humans," American Journal of Physiology, vol. 273, no. 6, pp. F1013-F1022, 1997.

[252] M. G. Hall, L. Quignodon, and B. Desvergne, "Peroxisome proliferator-activated receptor $\beta / \delta$ in the brain: facts and hypothesis," PPAR Research, vol. 2008, Article ID 780452, 10 pages, 2008.

[253] H. Sundvold, A. Brzozowska, and S. Lien, "Characterisation of bovine peroxisome proliferator-activated receptors $\gamma 1$ and $\gamma 2$ : genetic mapping and differential expression of the two isoforms," Biochemical and Biophysical Research Communications, vol. 239, no. 3, pp. 857-861, 1997.

[254] P. García-Rojas, A. Antaramian, L. González-Dávalos et al., "Induction of peroxisomal proliferator-activated receptor $\gamma$ and peroxisomal proliferator-activated receptor $\gamma$ coactivator 1 by unsaturated fatty acids, retinoic acid, and carotenoids in preadipocytes obtained from bovine white adipose tissue," Journal of Animal Science, vol. 88, no. 5, pp. 1801-1808, 2010.

[255] H. Meng, H. Li, and Y. X. Wang, "Characterization of tissue expression of peroxisome proliferator activated receptors in the chicken," Acta Genetica Sinica, vol. 31, no. 7, pp. 682-687, 2004.

[256] A. J. Vidal-Puig, R. V. Considine, M. Jimenez-Liñan et al., "Peroxisome proliferator-activated receptor gene expression in human tissues: effects of obesity, weight loss, and regulation by insulin and glucocorticoids," Journal of Clinical Investigation, vol. 99, no. 10, pp. 2416-2422, 1997.

[257] L. Fajas, D. Auboeuf, E. Raspé et al., "The organization, promoter analysis, and expression of the human PPAR $\gamma$ gene," Journal of Biological Chemistry, vol. 272, no. 30, pp. 18779-18789, 1997.

[258] L. F. Michael, M. A. Lazar, and C. R. Mendelson, "Peroxisome proliferator-activated receptor $\gamma 1$ expression is induced during cyclic adenosine monophosphate-stimulated differentiation of alveolar type II pneumonocytes," Endocrinology, vol. 138, no. 9, pp. 3695-3703, 1997.

[259] A. Rogue, M. P. Renaud, N. Claude, A. Guillouzo, and C. Spire, "Comparative gene expression profiles induced by PPAR $\gamma$ and PPAR $\alpha / \gamma$ agonists in rat hepatocytes," Toxicology and Applied Pharmacology, vol. 254, no. 1, pp. 18-31, 2011.

[260] S. Kersten, S. Mandard, N. S. Tan et al., "Characterization of the fasting-induced adipose factor FIAF, a novel peroxisome proliferator-activated receptor target gene," Journal of Biological Chemistry, vol. 275, no. 37, pp. 28488-28493, 2000.

[261] M. Lu, D. A. Sarruf, S. Talukdar et al., "Brain PPAR- $\gamma$ promotes obesity and is required for the insuling-sensitizing effect of thiazolidinediones," Nature Medicine, vol. 17, no. 5, pp. 618-622, 2011.

[262] K. K. Ryan, B. Li, B. E. Grayson, E. K. Matter, S. C. Woods, and R. J. Seeley, "A role for central nervous system PPAR- $\gamma$ in the regulation of energy balance," Nature Medicine, vol. 17, no. 5, pp. 623-626, 2011. 


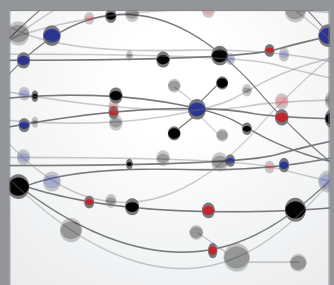

The Scientific World Journal
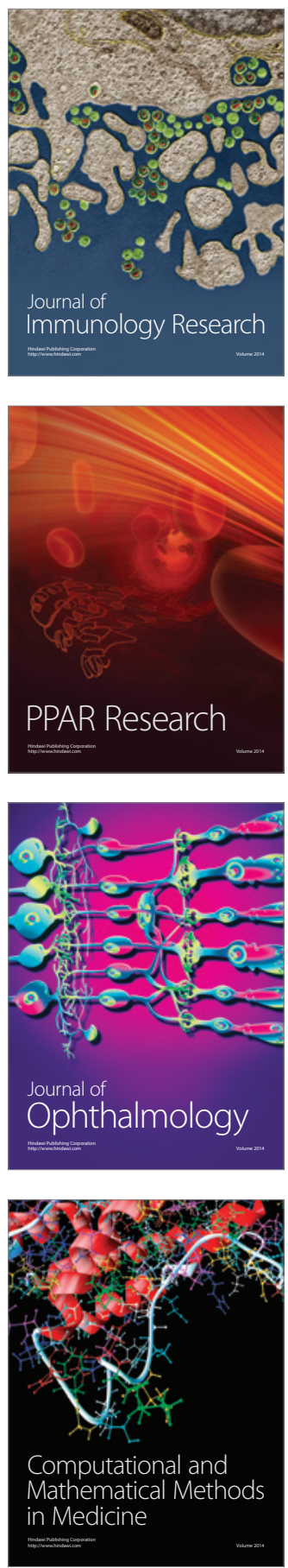

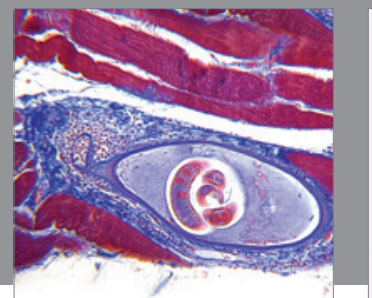

Gastroenterology

Research and Practice
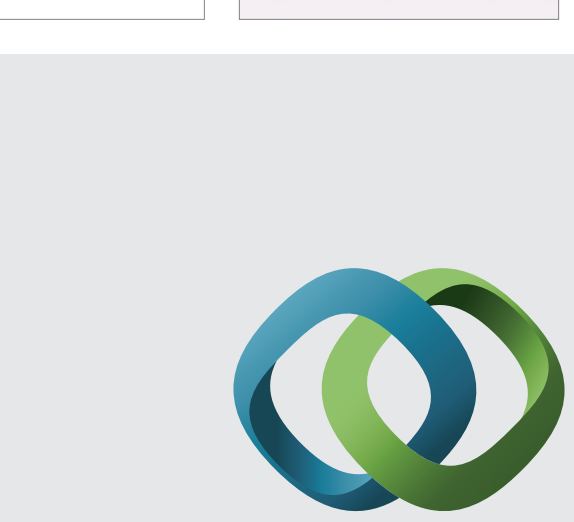

\section{Hindawi}

Submit your manuscripts at

http://www.hindawi.com
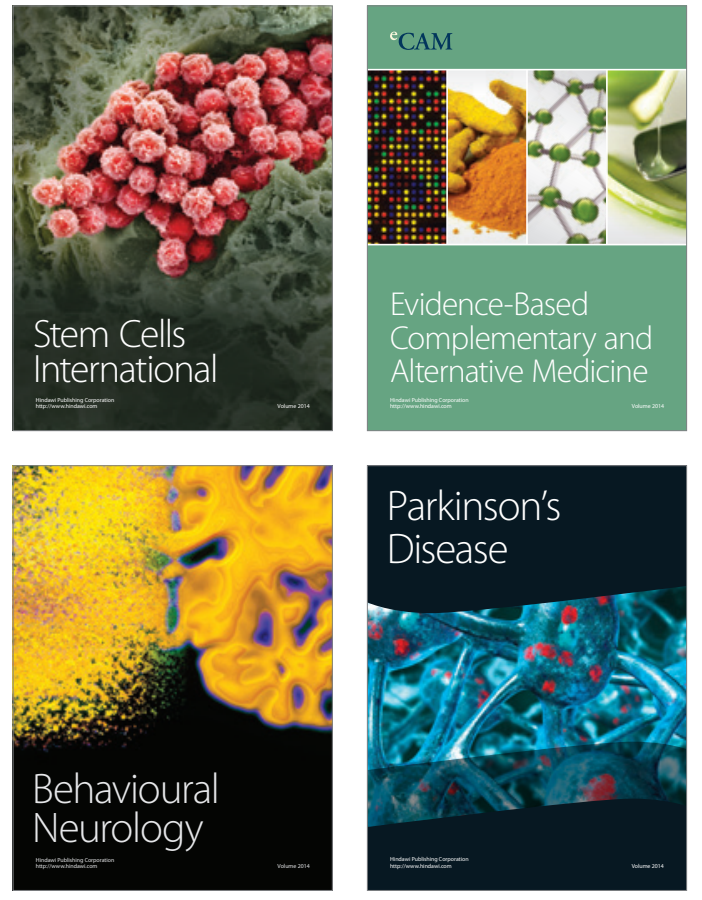
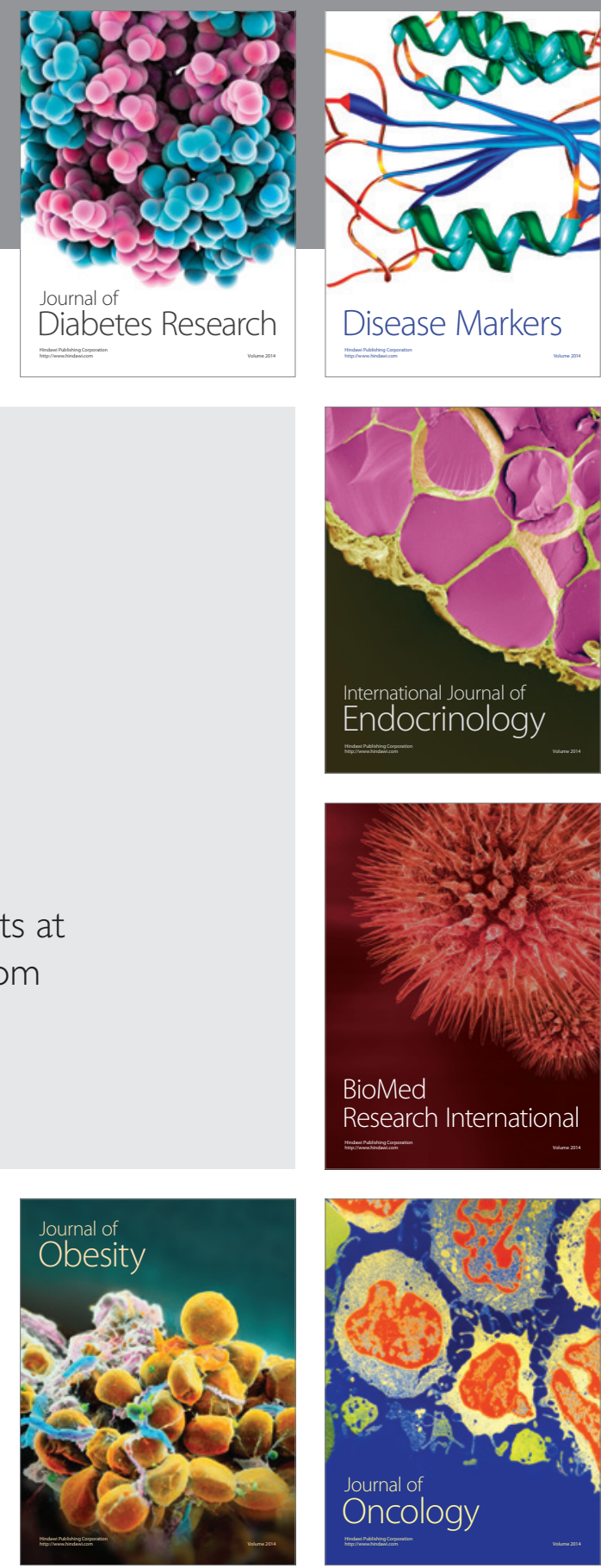

Disease Markers
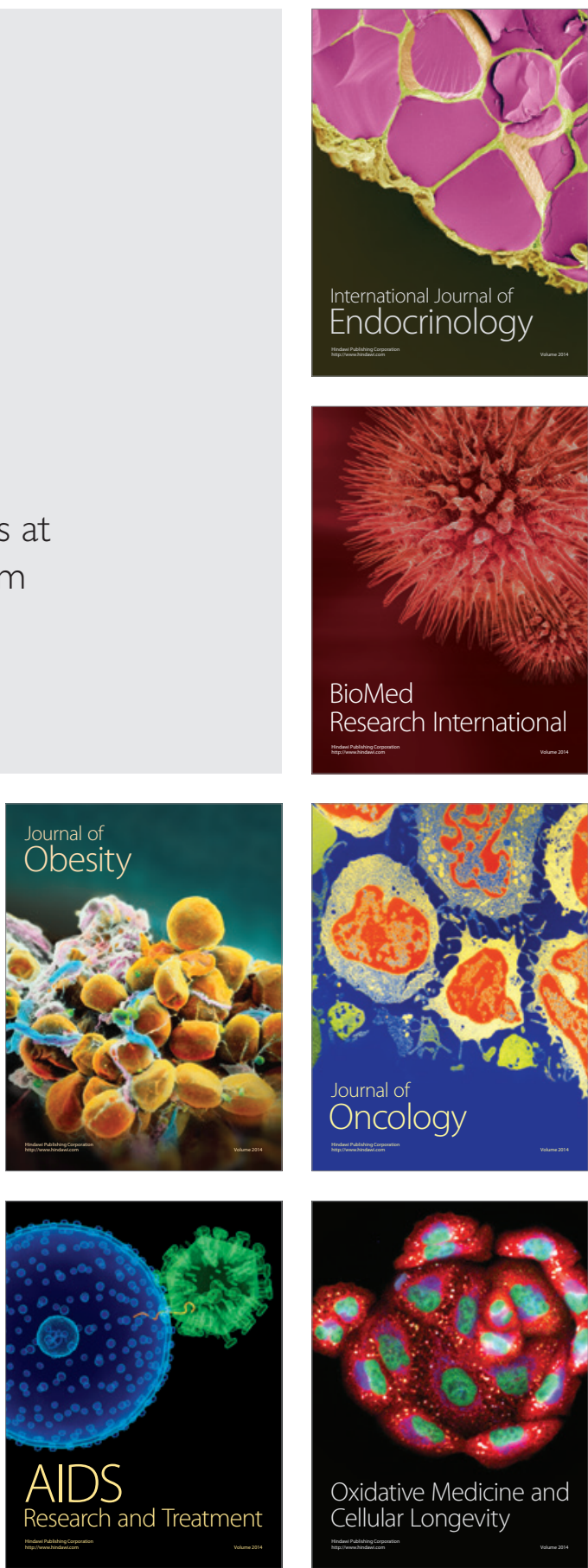